\title{
Especificação de Processos de Apoio Gerencial ao Processo de Testes de Software
}

\author{
Jeanne de Castro Trovão, Arilo Claudio Dias Neto \\ Instituto de Computação - Universidade Federal do Amazonas (UFAM) \\ Av. Rodrigo Otávio, 6200 - Coroado I - 69077-000 - Manaus - AM - Brasil \\ \{jeanne.trovao, arilo\} @icomp.ufam.edu.br
}

\begin{abstract}
Software companies are always concerned about improving the quality of their products and processes. Several strategies can applied to reach processes quality. One of them consists in the integration of support processes that assist the management of the main process and may be applied when required, contributing to the success and the quality of the main process and its products. When talking about software product quality, we can cite software testing activities. Software testing requires an appropriate management of its process so that the tests achieve the expected success and quality, within the defined time and budget. To aid this management, support processes can be integrated into the software testing process. This paper presents the specification of two processes of managerial support to the Software Testing Process, the Test Risks Management Process and the Test Human Resources Management Process, in order to contribute to the management of testing activities. These processes were defined based on several maturity models and norms/standards. In order to evaluate the proposed processes, a peer review was conducted with experts in the fields related to the specified processes and the results of this evaluation suggest that the proposed processes are appropriate and can be integrated into the testing process.
\end{abstract}

Resumo. Empresas de software estão sempre preocupadas em melhorar a qualidade de seus produtos e processos. Diversas estratégias podem ser aplicadas visando à obtenção de qualidade de processos. Uma delas consiste na integração de processos de apoio, que são aqueles que auxiliam um processo principal, contribuindo para o sucesso e qualidade deste processo e de seus produtos. Quando se fala em qualidade de produto de software, se remete às atividades de teste de software. Teste de software requer um gerenciamento adequado de seu processo para que os testes alcancem o sucesso e qualidade esperados, dentro do prazo e orçamento definidos. Para auxiliar este gerenciamento, processos de apoio gerencial podem ser integrados ao processo de testes de software. Este artigo apresenta a definição de dois processos de apoio ao processo de testes, Processo de Gerência de Riscos de Teste e Processo de Gerência de Recursos Humanos de Teste, visando contribuir com o gerenciamento das atividades de testes. Esses processos foram definidos tendo-se como base diversos modelos de maturidade e normas técnicas. Para avaliar os processos propostos, uma revisão por pares foi conduzida com especialistas das áreas referentes aos processos especificados e os resultados dessa avaliação sugerem que os processos aqui definidos estão adequados e possibilitam a aplicação deles de forma integrada ao processo de testes. 


\section{Introdução}

As atividades de teste de software possuem um papel fundamental no desenvolvimento de um software como mecanismo de apoio à garantia da qualidade do produto [Pressman 2010]. No entanto, apesar da notável importância do gerenciamento do processo de testes para que ele obtenha sucesso, observam-se na literatura técnica da área de testes um conjunto limitado de abordagens que apoiam essa atividade e, normalmente, estas abordagens são propostas para um contexto específico [Bertolino 2004].

De acordo com o Software Engineering Institute [SEI 2010], "a qualidade de um sistema ou produto é amplamente influenciada pela qualidade do processo utilizado". Trazendo este conceito para a área de teste de software, supõe-se que o sucesso dos testes em um projeto de software também seja influenciado pela qualidade do processo aplicado para seu gerenciamento. A qualidade do processo de testes terá um impacto direto na melhoria na qualidade da execução dos testes e, consequentemente, de seus resultados. Uma forma de contribuir com a qualidade de um processo é a partir de processos de apoio aplicados a um processo principal. Processo de apoio é aquele cujas atividades presentes nele não fazem parte das atividades mais importantes para a obtenção de um produto principal, porém auxiliam na realização desta tarefa, garantindo o apoio necessário ao funcionamento adequado do processo principal, aumentando sua eficiência e ajudando no controle e gerenciamento do processo principal [ISO/IEC 2008] [SEI 2010].

$\mathrm{Na}$ literatura técnica, poucos artigos discutem sobre processos de apoio especializados para o processo de testes [Trovão e Dias-Neto 2014]. Essa carência se torna um problema, pois o processo de testes possui características específicas quando comparado a outros processos de software, como por exemplo, recursos, técnicas e ferramentas específicos para a realização das atividades de teste [Myers 2004]. Essas características o impedem de utilizar as mesmas instâncias de processos de apoio existentes para o processo de desenvolvimento de software, sem que haja uma adequação para atender às necessidades da área de testes. Algumas abordagens têm sido propostas na literatura técnica para apoiar a avaliação de qualidade de processos de teste de software, dentre as quais podem ser citados: TPI (Test Process Improvement) [Sogeti 2009], TMMi (Test Maturity Model Integration) [TMMi Foundation 2012] e o MPT.BR (Modelo de Melhoria do Processo de Teste Brasileiro) [SOFTEX Recife 2011]. O apoio prestado por essas abordagens costuma servir como base para a introdução de práticas que visam aumentar a qualidade do processo de testes. No entanto, essas fontes não definem os processos que podem ser utilizados como apoio, nem como realizar a integração dos mesmos, de forma similar ao que ocorre com os modelos e normas de avaliação da qualidade do processo de desenvolvimento de software, como CMMI-DEV (Capability Matury Model Integration - Development) [SEI 2010], MR-MPS-SW (Modelo de Referência MPS para Software) [SOFTEX 2012] e ISO/IEC 12207 [ISO 2008] e PMBOK (Project Management Body of Knowledge) [PMI 2013].

Neste contexto, visando diminuir a carência de atividades que apoiam o gerenciamento do processo de teste, este artigo apresenta como objetivo a especificação de atividades de apoio gerencial relacionadas aos processos de Gerência de Recursos Humanos e Gerência de Riscos no contexto de Teste de Software visando contribuir com a qualidade e a eficiência no gerenciamento do seu processo.

A seguinte metodologia foi designada para o desenvolvimento desse trabalho: inicialmente foi realizada uma pesquisa sobre processos de apoio descritos na literatura técnica, baseando-se nas normas e modelos de maturidade citados acima (ISO/IEC 12207, TMMi, CMMI, MPT.BR e MR-MPS-SW), avaliando sua aplicação ao processo de testes. 
O objetivo foi a seleção dos processos de apoio que fariam parte do escopo deste trabalho (Processo de Gerência de Riscos de Teste e o Processo de Gerência de Recursos Humanos de Teste). Em seguida, foi conduzido um mapeamento sistemático sobre os processos de apoio selecionados a fim de caracterizar o estado da arte sobre a aplicação desses processos no contexto de testes e extrair possíveis contribuições para a implementação da abordagem. A análise dos processos em normas e modelos de maturidade, juntamente com a caracterização do estado da arte, possibilitou a especificação dos processos de apoio selecionados, em adequação a tais normas e modelos e contemplando práticas de apoio identificadas na literatura técnica. Para avaliar os processos propostos, uma revisão por pares foi conduzida com 5 especialistas das áreas referentes aos processos especificados. Comentários com recomendações para evolução dos processos foram feitos, os processos foram ajustados de forma a possibilitar a aplicação deles de forma integrada ao processo de testes na indústria de software.

Este artigo está organizado da seguinte forma: a Seção 2 aborda a aplicação de processos de apoio a processos de software, cita o processo de teste utilizado neste trabalho para integrar aos processos de apoio propostos e apresenta trabalhos relacionados que envolvem a aplicação de processos de apoio em processos de teste ou outros processos de software; a Seção 3 apresenta o Processo de Gerência de Riscos de Teste; a Seção 4 apresenta o Processo de Gerência de Recursos Humanos de Teste; a Seção 5 apresenta a avaliação dos processos; e, por fim, a Seção 6 apresenta as considerações finais e trabalhos futuros.

\section{Fundamentação Teórica}

\subsection{Processos de Apoio em Normas e Modelos de Maturidade}

Processos de apoio são processos cujas atividades presentes nele não fazem parte das atividades mais importantes necessárias para a obtenção de um produto principal (atividades realizadas pelo processo principal). No entanto, eles auxiliam na realização dessa tarefa, garantindo o apoio necessário ao funcionamento adequado do processo principal, aumentando sua eficiência e ajudando no controle e gerenciamento do processo principal [ABNT 1998] e CMMI [SEI 2010].

Algumas normas, como a ISO/IEC 12207 (2008), modelos de melhoria de qualidade do software e do processo de teste, como CMMI-DEV [SEI 2010], TMMi [TMMi Foundation 2012], MR-MPS-SW [SOFTEX 2012], MPT.BR [SOFTEX Recife 2011], e até guias como o PMBOK [PMI 2013] descrevem processos de apoio e organizacionais para o processo de software. Porém, eles não especificam os processos de apoio com os detalhes necessários para sua implantação em organizações de software. Apenas são sugeridos práticas e resultados esperados para estes processos que podem ser utilizados no contexto de engenharia (teste) de software para apoiar no gerenciamento das suas atividades.

Entre os processos de apoio que normalmente se aplicam em Engenharia de Software, podem ser citados como exemplo alguns processos previstos pela norma ISO/IEC 12207 e modelos de maturidade CMMI-DEV e MR-MPS-SW: Gerência de Projetos; Gerência de Riscos; Gerência de Decisões; Verificação \& Validação; Gerência de Reutilização; Gerência de Recursos Humanos; Medição; Garantia da Qualidade do Produto e do Processo; Gerência de Portfólio de Projetos; Gerência de Configuração; Aquisição; Gerência de Requisitos; Gerência de Informação; Gerência de Documentação; Acompanhamento e Controle de Projeto; e Revisão. 
Os diferentes processos de apoio presentes em normas e modelos de qualidade possuem sua importância quando contextualizados ao processo de testes de software. Nessa pesquisa, foi investigado quais e como os processos de apoio podiam ser aplicados no processo de testes para, posteriormente, prover uma especificação que simplificasse a aplicação desses processos de apoio em projetos de teste de software.

Visto que o objetivo desta pesquisa é a definição de processos de apoio a serem aplicados de forma integrada ao processo de teste de software, observou-se que suprir a carência de todos os processos de apoio para o processo de teste seria inviável, pois exigiria um tempo muito maior que o especificado para a realização deste trabalho. Portanto, para selecionar quais processos seriam priorizados para serem especificados, foi feita uma análise nos modelos e normas citados anteriormente para identificar quais processos de apoio poderiam contribuir de forma mais direta para o sucesso do processo de teste. Como resultado da pesquisa, foram encontrados 9 processos: Gerência de Infraestrutura, Gerência de Portfólio, Gerência de Recursos Humanos, Gerência de Configuração, Gerência de Riscos, Gerência de Informação, Medição, Engenharia de Domínio e Gerência de Reutilização.

Em seguida, foi feita uma análise com esses 9 processos verificando como eles poderiam dar suporte ao processo de testes. Entre eles, os 5 mais relevantes para o processo de teste de acordo com os resultados da análise e na perspectiva dos pesquisadores eram: Gerência de Portfólio, Gerência de Recursos Humanos, Gerencia de Configuração, Gerência de Riscos e Gerência de Reutilização. Tais processos foram categorizados como processos de apoio técnico (Gerência de Configuração e Gerência de Reutilização) e gerencial (Gerência de Riscos, Gerência de Recursos Humanos, Gerência de Portfólio). Neste trabalho, com base nas contribuições identificadas pela análise sobre cada processo de apoio realizadas a partir dos resultados de um mapeamento sistemático, com resultados parciais descritos neste artigo, foram escolhidos dois destes processos gerenciais (Gerência de Riscos e Gerência de Recursos Humanos). Esses processo foram especificados seguindo as diretrizes dos principais modelos e normas de apoio à qualidade de processo de software, que priorizam o aspecto gerencial antes do técnico (os processos gerenciais, em geral, estão em níveis de maturidade inferiores em relação aos técnicos). Outros processos de apoio poderiam ser escolhidos, porém em um primeiro momento optou-se por desenvolver este trabalho com dois processos, e como trabalhos futuros novos processos de apoio serão definidos.

\subsection{Processos de Teste de Software}

Um processo de teste tem como objetivo estruturar as atividades, os artefatos, os papéis e as responsabilidades do teste de software, permitindo organização e controle de todo o ciclo do teste, agregando qualidade ao software [Myers 2004]. Apesar de toda a complexidade deste processo, existem atividades necessárias que devem ser consideradas para que ele seja executado de forma adequada e com o menor custo possível. Estas necessidades podem ser supridas com a integração de processos que possam dar suporte a elas durante a execução do processo de teste.

O Processo de Testes de Software adotado para esse trabalho é resultado do trabalho de dissertação de mestrado publicado em [Dias-Neto 2006], e suas atividades do processo de testes foram definidas baseando-se nas recomendações do IEEE STD 829 (2008), atividades descritas na literatura de teste software e de atividades de gerência de projetos de software, obtidas a partir de diversas fontes de conhecimento, como CMMIDEV [SEI 2010] e PMBOK [PMI 2013] ]), características que levaram à escolha deste processo. Já os artefatos produzidos ao longo do processo de testes são os documentos especificados pelo IEEE STD 829 (2008). Esse processo utiliza fontes similares às 
utilizadas para a definição da norma ISO/IEC/IEEE 29119-2 (2013). Ele é dividido nos subprocessos de Planejamento dos Testes e Execução dos Testes (Figura 1), incluindo as suas macroatividades, papéis e artefatos, seguindo a notação proposta em [Villela 2004].

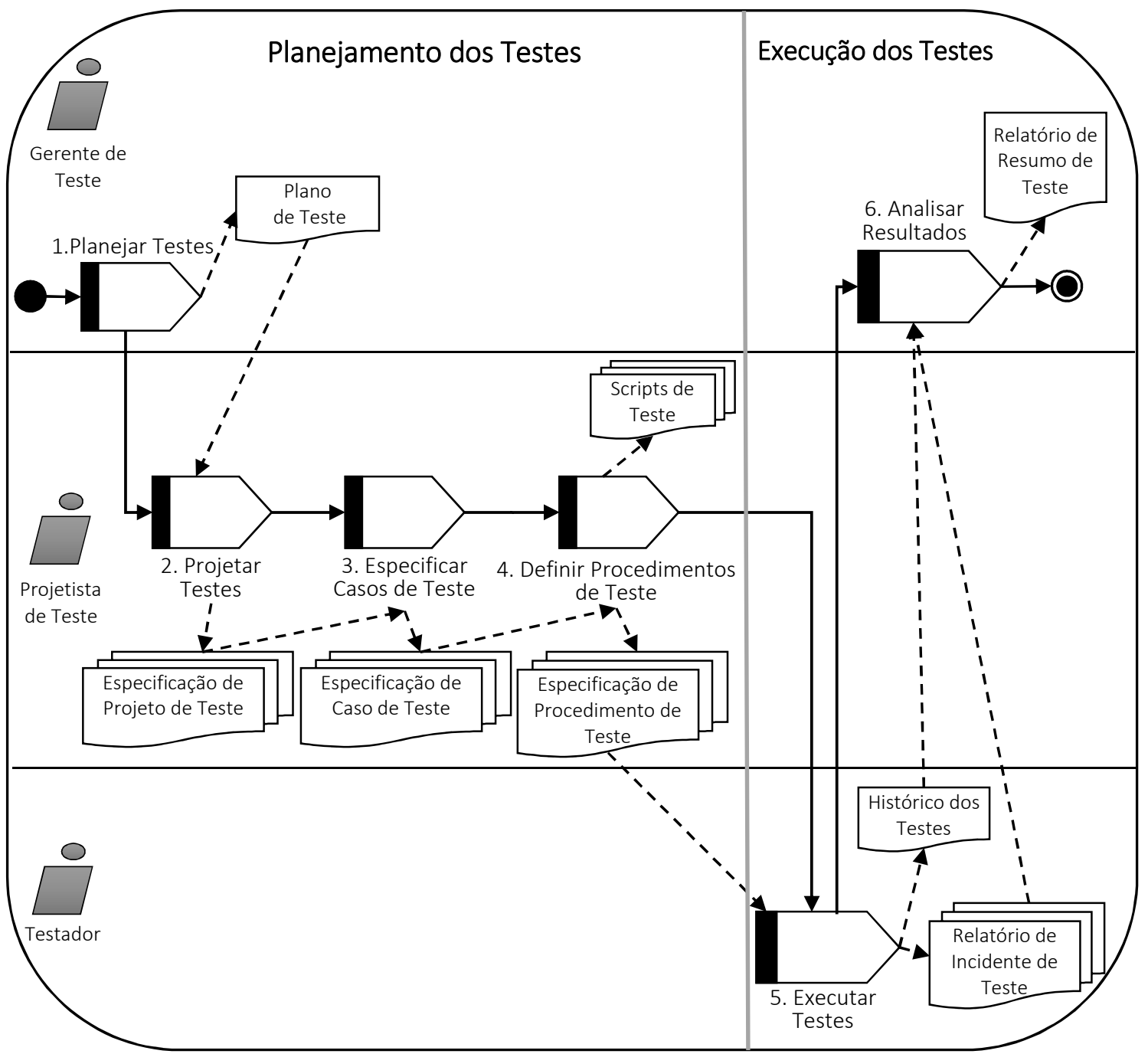

Figura 1. Subprocessos que compõem o processo de testes de [Dias-Neto 2006].

Os papéis associados a esse processo de testes estão descritos na Tabela 1.

Tabela 1. Papéis associados ao processo de testes de software [Dias-Neto 2006].

\begin{tabular}{|l|l|}
\hline Papel & Descrição \\
\hline Gerente de Teste & Responsável pelo planejamento e controle dos testes. \\
\hline Projetista de Teste & $\begin{array}{l}\text { Responsável pelo projeto dos testes, incluindo seleção de abordagens de } \\
\text { teste e identificação e especificação dos casos e procedimentos de teste. }\end{array}$ \\
\hline Testador & $\begin{array}{l}\text { Responsável pela execução dos procedimentos de teste especificados a } \\
\text { fim de detectar falhas no software e registro dos incidentes ocorridos } \\
\text { durante os testes. }\end{array}$ \\
\hline
\end{tabular}

Os artefatos associados a esse processo de testes estão descritos na Tabela 2.

Tabela 2. Artefatos produzidos pelo processo de testes [Dias-Neto 2006].

\begin{tabular}{|l|l|}
\hline Artefato & Descrição \\
\hline
\end{tabular}




\begin{tabular}{|l|l|}
\hline Plano de Teste & $\begin{array}{l}\text { Apresenta o planejamento para execução dos testes, incluindo o objetivo, } \\
\text { escopo, abordagem de teste a ser seguida, recursos físicos e humanos e } \\
\text { cronograma das atividades de teste. Identifica os itens e funcionalidades a } \\
\text { serem testadas, as características dos itens que deverão ser testadas, } \\
\text { tarefas a serem realizadas e os riscos associados às atividades de teste. }\end{array}$ \\
\hline $\begin{array}{l}\text { Especificação de } \\
\text { Projeto de Teste }\end{array}$ & $\begin{array}{l}\text { Refina a abordagem de teste a ser seguida para avaliação de um (ou vários) } \\
\text { item de teste em relação a uma característica (ou uma combinação de } \\
\text { características) de teste que tenha sido especificada no Plano de Teste. } \\
\text { Esse documento identifica os casos e os procedimentos de teste e } \\
\text { apresenta os critérios para aprovação do(s) item(s) de teste avaliado(s) } \\
\text { nesse projeto de teste específico. }\end{array}$ \\
\hline $\begin{array}{l}\text { Especificação de } \\
\text { Caso de Teste }\end{array}$ & $\begin{array}{l}\text { Define um caso de teste, incluindo dados de entrada, resultados esperados, } \\
\text { ações e condições gerais para a sua execução. }\end{array}$ \\
\hline $\begin{array}{l}\text { Especificação de } \\
\text { Procedimento de } \\
\text { Teste }\end{array}$ & \begin{tabular}{l} 
Especifica os passos para executar um ou um conjunto de casos de teste. \\
\hline $\begin{array}{l}\text { Histórico dos } \\
\text { Testes }\end{array}$
\end{tabular}$\quad \begin{array}{l}\text { Apresenta registros cronológicos dos detalhes relevantes relacionados à } \\
\text { execução dos testes. }\end{array}$ \\
\hline $\begin{array}{l}\text { Relatório de } \\
\text { Incidente de Teste }\end{array}$ & $\begin{array}{l}\text { Documenta qualquer evento anormal, ou seja, que não era esperado pelo } \\
\text { testador, que ocorra durante a execução dos casos e procedimentos de teste } \\
\text { e que requeira análise posterior. }\end{array}$ \\
\hline $\begin{array}{l}\text { Relatório de } \\
\text { Resumo de Teste }\end{array}$ & $\begin{array}{l}\text { Apresenta de forma resumida os resultados obtidos durante os testes e } \\
\text { provê avaliações baseadas nesses resultados. }\end{array}$ \\
\hline
\end{tabular}

A Figura 2 apresenta o detalhamento das atividades que compõem a macroatividade "1. Planejar Testes", previamente mostrada na Figura 1. Analisando as atividades da Figura 2, pode ser observado que as atividades "2. Identificar Riscos", "4. Planejar Recursos Humanos" e "8. Especificar Necessidade de Treinamento" são consideradas atividades externas, pois são realizadas por meio de processos de apoio, a serem descritos nas próximas seções desse artigo.

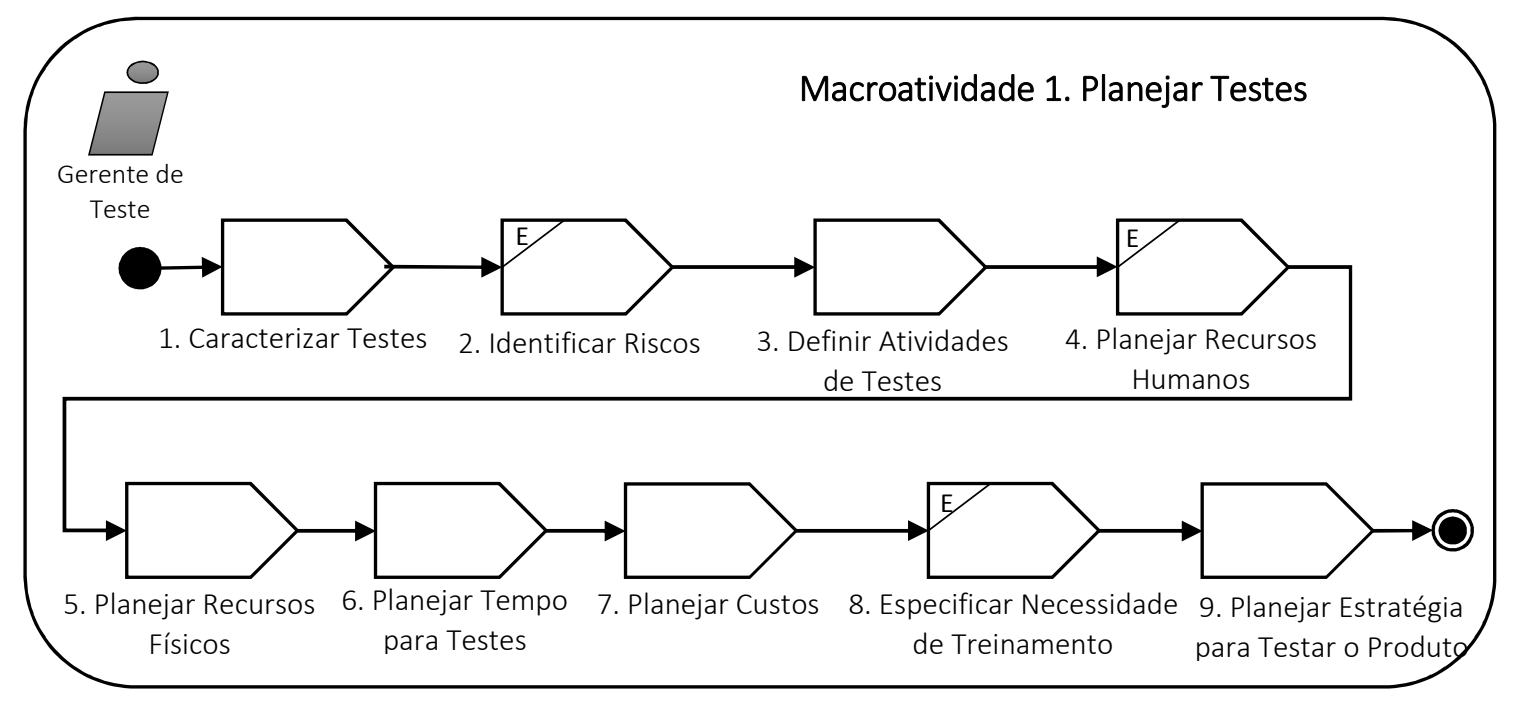

Figura 2. Detalhamento da Macroatividade Planejar Testes (Figura 1).

A atividade "2. Identificar Riscos" é realizada pelo subprocesso "Planejamento de Riscos de Teste" que faz parte do processo de "Gerência de Riscos de Teste" (Seção 3). As outras duas atividades externas são realizadas por meio de macroatividades do processo de "Gerência de Recursos Humanos de Teste", (Seção 4). A atividade "4. Planejar Recursos Humanos" é realizada pela macroatividade "1. Planejar Recursos 
Humanos de Teste" e a atividade " 8 . Especificar Necessidade de Treinamento" é realizada pela macroatividade "2. Planejar Obtenção de Conhecimento". Este processo e os processos de apoio deste trabalho utilizam uma notação gráfica de processos adaptada de [Villela 2004].

Além das interações explícitas com o Processo de Teste ilustradas nos processos de apoio nas próximas seções (Figuras 3, 4 e 5), também foram incluídas ao longo do Processo de Teste várias interações especificando como o gerenciamento de riscos e de recursos humanos influencia na execução de algumas de suas atividades. Essas interações são descritas por meio dos campos Relação com o Processo de Gerência de Riscos e Relação com o Processo de Gerência de Recursos Humanos presente na descrição das atividades do processo de teste. A Tabela 3 mostra um exemplo dessa interação na descrição da subatividade "2.3 Identificar Casos e Procedimento de Teste", que faz parte da macroatividade "2. Projetar Testes" do Subprocesso de Planejamento dos Testes.

Tabela 3. Descrição de Subatividade do Processo de Testes de Software.

\begin{tabular}{|l|l|}
\hline Subatividade: & 2.3. Identificar Casos e Procedimento de Teste \\
\hline Descrição: & $\begin{array}{l}\text { Casos de Teste são pontos essenciais na execução dos testes em software. } \\
\text { Testar exaustivamente ou testar todas as combinações de entradas } \\
\text { possíveis é inviável [Myers 2004]. Com isso, a seleção de casos de teste } \\
\text { corretos é um fator essencial para o sucesso da atividade de teste. Durante } \\
\text { esta atividade, deve ser identificado o conjunto de casos e procedimentos } \\
\text { de teste para avaliar o item de teste e a característica selecionada para o } \\
\text { projeto de teste em questão. }\end{array}$ \\
\hline $\begin{array}{l}\text { Relação com o } \\
\text { Processo de GR: }\end{array}$ & $\begin{array}{l}\text { Esta atividade deve ser realizada de acordo com a prioridade dos riscos } \\
\text { associados ao conjunto de casos e procedimentos de teste a serem } \\
\text { selecionados. }\end{array}$ \\
\hline $\begin{array}{l}\text { Relação com o } \\
\text { Processo de } \\
\text { GRH: }\end{array}$ & $\begin{array}{l}\text { Nesta atividade também é realizada a alocação dos casos e procedimentos } \\
\text { de teste identificados aos recursos humanos responsáveis pela sua } \\
\text { especificação, de acordo com o perfil de cada recurso, conforme método } \\
\text { de alocação proposto por [Miranda et al. 2010]. }\end{array}$ \\
\hline
\end{tabular}

\subsection{Trabalhos Relacionados}

Os trabalhos relacionados a essa pesquisa são divididos em duas categorias: trabalhos que aplicam os mesmos processos de apoio especificados nessa pesquisa ao contexto de testes e trabalhos que aplicam outros processos de apoio ao processo de testes.

$\mathrm{Na}$ tentativa de encontrar trabalhos relacionados à gerência de riscos e gerência de recursos humanos, foi realizado o mapeamento sistemático em 2013. Um protocolo de busca foi projetado para a condução do mapeamento sistemático, conforme definido a seguir. A questão da pesquisa definida para o mapeamento sistemático possui apenas uma questão principal:

"Quais são os métodos, técnicas, abordagens e ferramentas existentes sobre processos de apoio gerencial aplicados ao processo de testes de software?"

Os componentes da pergunta foram definidos de forma específica para cada processo de apoio de acordo com o padrão PICO (population, intervention, comparison, outcomes) [Kitchenham e Charters 2007]. A partir desses elementos foi definida a string de busca formada pelos seguintes elementos:

- População: Processos de teste. 
- Intervenção: Processo de gerência de recursos humanos ou Processo de Gerência de Riscos.

- Comparação: Não se aplica.

- Resultados: Processos, relatos, abordagens, métodos, metodologias.

As fontes de pesquisa foram as bibliotecas digitais IEEE Explore, ACM Digital Library e Scopus, além de fontes com busca manual, como o acervo BDBComp e anais dos eventos SBQS, SBES e WAMPS. Com o resultado das buscas nas fontes de pesquisa, os artigos retornados passaram por dois filtros para selecionar os artigos que eram de fato relevantes para a pesquisa. O primeiro filtro foi realizado com a leitura apenas dos títulos e resumos dos artigos retornados, e a partir desses foi feito o segundo filtro, com a leitura dos artigos por completo. A Tabela 4 a seguir indica a quantidade total de artigos encontrados.

Tabela 4. Resultado do Mapeamento Sistemático.

\begin{tabular}{|l|c|c|c|}
\hline \multicolumn{1}{|c|}{ Processo } & Retornados & $\begin{array}{c}\text { Após 1 } \\
\text { (Título }+ \\
\text { Abstract) }\end{array}$ & $\begin{array}{c}\text { Após 2 } \\
\text { (Artigo } \\
\text { Completo) }\end{array}$ \\
\hline Gerência de Recursos Humanos & 105 & 6 & 2 \\
\hline Gerência de Riscos & 527 & 30 & 10 \\
\hline Total & $\mathbf{8 5 2}$ & $\mathbf{3 9}$ & $\mathbf{1 2}$ \\
\hline
\end{tabular}

Na Tabela 5, é possível ver que a aplicação dos artigos encontrados sobre o processo de Gerência de Recursos Humanos (GRH) para o processo de testes é destinada ao contexto de teste terceirizados, onde é preciso ter um alto controle desses recursos, já que costumam receber muitos projetos em um curto período de tempo. Nenhum dos artigos desse processo usou normas ou modelos para definir sua aplicação e apenas um deles avaliou a abordagem proposta verificando sua aplicabilidade.

Para o processo de Gerência de Riscos (GRI), foram encontradas algumas aplicações para o processo de testes, dentre as quais se destacaram a priorização de casos de teste e a conformidade com o cronograma previsto como sendo os principais motivos para se aplicar esse processo em testes. A maioria das abordagens $(80 \%)$ se preocupou em avaliar sua proposta e observou fatores diversos para fazer a avaliação. Nesse processo, a conformidade com modelos de melhoria de processo foi levada em conta, principalmente em relação ao CMMI [SEI 2010], cujo modelo serviu de referência para duas das dez abordagens encontradas.

A seguir são apresentados os trabalhos selecionados a partir do mapeamento sistemático e uma análise de suas contribuições para a pesquisa.

O trabalho de [Li et al. 2013] discute alguns pontos a serem levados em conta ao fazer o gerenciamento de recursos humanos e gerenciamento de riscos para o processo de testes no contexto de teste terceirizado, ou seja, está relacionado a um contexto específico do cenário de testes. Além disso, não especifica nenhum dos processos de apoio nem está associado a algum modelo ou norma de qualidade de software.

Tabela 5. Resultado de Análise dos Dados do Mapeamento Sistemático

\begin{tabular}{|c|c|c|}
\hline $\begin{array}{c}\text { Processos / } \\
\text { Critérios }\end{array}$ & GRH & GRI \\
\hline
\end{tabular}




\begin{tabular}{|c|c|c|}
\hline $\begin{array}{l}\text { Aplicação } \\
\text { em Testes }\end{array}$ & $\begin{array}{l}\text { - Testes terceirizados (2) } \\
\text { - Eficácia na realocação } \\
\text { de pessoas (1) }\end{array}$ & $\begin{array}{l}\text { - Priorização de casos de teste (4) } \\
\text { - Estimativa de tempo necessário para testar (1) } \\
\text { - Aumento da taxa de detecção de defeitos (1) } \\
\text { - Conformidade com o orçamento previsto (3) } \\
\text { - Conformidade com o cronograma previsto (6) } \\
\text { - Avaliação da confiabilidade após os testes (1) }\end{array}$ \\
\hline Avaliação & $\begin{array}{l}\text { 50\% (1) avaliou: } \\
\text { Aplicabilidade }\end{array}$ & $\begin{array}{l}\text { 80\% (8) avaliou: } \\
\text { - Custo-benefício (2) } \\
\text { - Taxa e tempo de detecção de falhas (2) } \\
\text { - Severidade das falhas (2) } \\
\text { - Eficácia em identificar riscos (2) } \\
\text { - Produtividade dos testes (1) }\end{array}$ \\
\hline $\begin{array}{l}\text { Modelo / } \\
\text { Norma }\end{array}$ & $0 \%$ associou & $20 \%$ (2) associou: CMMI (2) e TMM (1) \\
\hline
\end{tabular}

O trabalho de [Larsson et al. 2008] propõe sugestões de melhorias para o processo de realocação de pessoas em projetos de teste. São sugeridas: 1) adoção de um template de documentação com informações de cada projeto para minimizar o tempo de adaptação de um consultor/testador ao ser realocado para outro projeto; e 2) adoção de um template para registro das experiências de teste, a fim de que o conhecimento tácito possa ser compartilhado. Além de ser aplicado a um contexto específico que é o de teste de software terceirizado, o trabalho não especifica nenhum processo de apoio, porém, a aplicabilidade das sugestões de melhoria foi avaliada por meio de validação estática, com o uso de entrevistas ao Gerente de Projeto.

[Sherer 1991] apresenta uma abordagem para estimar a quantidade de tempo utilizada em testes baseando-se na probabilidade de riscos dos módulos do sistema. $\mathrm{O}$ trabalho descreve a aplicação do método para determinar a quantidade ideal de tempo que deve ser "gasta" na execução de testes por meio da avaliação de riscos proposta pelo método, levando em conta a avaliação do benefício obtido ao se realizar testes adicionais. $\mathrm{O}$ artigo defende que devemos testar até que as consequências da falha não mais justifiquem o custo do teste. Por fim, o custo-benefício obtido ao realizar testes com o uso do método é avaliado. Esse método foi citado como uma das práticas sugeridas para a priorização de riscos do projeto de testes no Processo de Gerência de Riscos de Teste, proposto neste artigo.

Baseado no processo de gerenciamento de riscos, o trabalho de [Yoon e Choi 2011] propõe um método de priorização de casos de testes (TCP) por meio da abordagem de teste baseado em riscos, utilizando o valor de exposição do risco (RE). O método busca obter a maior taxa de detecção de defeitos possível no menor tempo e avalia a eficácia do método de priorização verificando a taxa de detecção de defeitos da suíte de casos de testes e quão cedo eles são detectados, e também verifica a severidade dos riscos dos defeitos encontrados comparando com outra técnica de TCP.

O trabalho de [Bubevski 2010] descreve, implementa e avalia a abordagem chamada DMAIC (define, measure, analyse, improve, control), relacionada à metodologia Six Sigma, para avaliar e mitigar os riscos de um processo de testes em andamento. Seu objetivo é entregar o produto no tempo e alcançar as metas de qualidade. Esse trabalho não define um processo, mas apenas um modelo que possui relação com o modelo CMMI [SEI 2010] e foi avaliado em relação à sua eficácia em identificar os riscos do processo de software por meio da simulação do processo. 
[Paul 2001] sugere a realização de um mecanismo de ranking dos riscos de um cenário/função do sistema para ajudar a focalizar os testes para as funções de maior risco primeiro. Os riscos atribuídos aos casos de testes são baseados no risco da funcionalidade à qual ele está relacionado e nos riscos das condições dessa funcionalidade. Essa abordagem constitui uma das práticas sugeridas para a priorização de riscos do produto de testes no Processo de Gerência de Riscos de Teste, a ser apresentado nesse artigo.

[Stoelinga e Timmer 2009] apresentam um método para calcular o risco de um sistema depois de passar com sucesso um conjunto de teste, assim como um modo para calcular a qualidade de um dado conjunto de teste em relação ao risco. Primeiro é estimado o número de falhas que ainda restam e não foram detectadas pelos testes, depois é definido o risco da implementação por meio da gravidade das falhas restantes esperadas. Esse método é citado como uma prática sugerida para a análise de dados de riscos de testes no Processo de Gerência de Riscos de Teste deste trabalho, possibilitando um "retrato" da situação dos riscos de um sistema ao ser entregue.

[Lazić e Mastorakis 2005] oferecem uma abordagem para otimização do processo de testes de software com base na gerência dos riscos. É descrita a implementação do processo de gerenciamento de riscos, baseada em retorno sob investimento (ROI) e visa resolver problemas utilizando técnicas de modelagem e simulação (M\&S) para simulação de cenários de teste em vários níveis de abstração do software que a ser testado. Este trabalho integra o processo de gerência de riscos a um processo de testes para garantir baixos riscos no projeto, respeitando os limites do seu cronograma e orçamento e avalia a produtividade das atividades de teste em gerenciar um processo de testes estável (previsível e controlável) com o menor risco possível, a um preço e tempo acessível. Apesar de ter sido feita para um processo de testes específico, algumas práticas dessa abordagem puderam ser incluídas em mais de uma atividade do Processo de Gerência de Riscos de Teste.

[Souza et al. 2010] especifica um processo de testes baseado em risco (RBT) que possui atividades de um processo de testes comum. Para avaliar o processo foi realizado um estudo de caso para verificar se (i) a abordagem RBT pode encontrar defeitos mais rápido que uma abordagem não RBT e se (ii) os defeitos encontrados são aqueles que possuem maior severidade. Foi concluído que RBT realmente foca nas partes do software que são mais propensos a falhar e encontra os defeitos mais importantes mais cedo do que abordagem funcional, o que ajuda os gerentes de teste a fazerem melhor uso do tempo e recursos limitados. Diferente da abordagem desse artigo, esse trabalho relacionado não fornece um processo de apoio que possa ser usado de forma opcional, mas possui conclusões que ajudam a justificar a importância da aplicação da gerência de riscos no contexto de testes.

[Amland 2000] apresenta uma abordagem de teste de sistema baseado em riscos, porém com foco em riscos de negócios. Esse trabalho não especifica o processo de apoio, mas o processo de testes é mapeado dentro do processo de gerenciamento de riscos de engenharia de software. Foi realizado um estudo de caso para verificar a abordagem na prática e foi observado que o número de falhas encontradas foi igual ou menor que em versões anteriores da aplicação testada e que o projeto foi capaz de entregar versões de qualidade aceitável dentro de um tempo mais curto e com menos recursos do que o estimado. A forma de calcular a Exposição de Risco foi citada como prática sugerida ao definir critérios de avaliação de riscos no Processo de Gerência de Riscos de Teste desse trabalho. 
[Chen et al. 2002] propõe um método para realizar a priorização e seleção de casos de testes para o teste de regressão baseado em riscos. Foi realizado um experimento com 3 testadores experientes, cada um responsável por um componente de um sistema. Eles escolheram os testes para o teste de regressão manualmente de acordo com a sua experiência e ao mesmo tempo os autores aplicaram a abordagem proposta para escolher a suíte de teste para a regressão. Avaliaram a eficácia, o custo-benefício e a sensibilidade ao risco dos casos de teste priorizados para o teste de regressão e em todas as características, a suíte de testes selecionada com a abordagem proposta se saiu melhor. A forma de calcular a Exposição de Risco desta abordagem também foi citada como prática sugerida ao definir critérios de avaliação de riscos no Processo de Gerência de Riscos de Teste desse trabalho.

[Ericson et al. 1997] descreve um modelo para melhoria de testes baseado nos modelos CMM - Capability Maturity Model [Paulk et al. 1995] e TMM - Testability Maturity Model [Gelperin 1996]. O modelo não define atividades realmente, mas define metas que devem ser alcançadas em cada área chave. A parte de gerenciamento de riscos é chamada de "redução de risco" e é um dos 4 níveis existentes no modelo. O modelo foi avaliado com três casos de estudo, onde determinaram o "perfil de maturidade" de cada organização em relação a cada um dos níveis e buscando entender que motivos levaram aquelas organizações a estarem com aquele perfil.

Os dados extraídos dos artigos identificados no mapeamento sistemático (e descritos acima nesta seção) foram de grande utilidade para a definição dos processos dessa pesquisa, já que pode ser observada a aplicação de alguns deles na literatura técnica, a forma como foram avaliados e verificar pontos que necessitavam de mais atenção e que tentou-se cobrir nesta pesquisa. Além disso, algumas práticas adotadas por esses estudos foram utilizadas para enriquecer os processos de apoio a serem apresentados nesse artigo.

Mais detalhes sobre os trabalhos identificados podem ser encontrados na página www.icomp.ufam.edu.br/experts/processosapoio, que descreve com detalhes o estudo de mapeamento sistemático realizado para identificação de tais trabalhos.

\section{Processo de Gerência de Riscos de Teste}

O objetivo deste processo é prever os riscos que podem afetar as atividades de teste durante seu planejamento ou execução e estabelecer planos para eliminar ou diminuir o impacto destes riscos, de forma que o processo de teste possa seguir seu fluxo com o mínimo de problemas possíveis.

As categorias de riscos podem ser definidas como [Sommerville 2007]:

- Riscos de Projeto: afetam o cronograma ou os recursos do projeto;

- Riscos de Produto: afetam a qualidade ou o desempenho do software que está sendo desenvolvido;

- Riscos para os negócios: afetam a organização que desenvolve ou adquire o software. Os riscos pertencentes a esta última categoria devem ser gerenciados em nível de projeto de software e, portanto, não são tratados neste trabalho, já que o foco é o processo de testes.

\subsection{Papéis e Artefatos do Processo de Gerência de Riscos de Teste}

O papel existente neste processo é o do Analista de Riscos de Teste, responsável por todas as atividades referentes ao gerenciamento de risco e deve ter conhecimento suficiente sobre o processo, o domínio do software a ser testado e sobre diretrizes da organização que podem estar relacionadas com os riscos. Quando não há um profissional dedicado 
para este papel, o Gerente de Teste (ou na sua ausência, o Gerente de Projeto) assumiria esta responsabilidade.

Os artefatos gerados por este processo incluem:

- Plano de Riscos de Teste: descreve como o gerenciamento de riscos será executado, monitorado e controlado em um determinado projeto de teste;

- Registro de Riscos: onde os riscos identificados são documentados e todas as informações referentes a eles são armazenadas e atualizadas no decorrer do processo de riscos [PMI 2013] [IEEE 2008];

- Relatório de Dados de Riscos: um relatório final do processo de riscos e serve para comunicar a situação dos riscos no processo de teste, possibilitando a tomada de decisões e o registro de informações.

Os artefatos utilizados que não foram descritos aqui pertencem ao Processo de Teste de Software utilizado [Dias-Neto 2006], citados na Seção 2.2.

\subsection{Extração das Atividades do Processo de Gerência de Riscos de Teste}

As atividades que compõem o Processo de Gerência de Riscos de Teste propostas neste trabalho tiveram como principais referências os modelos TMMi [TMMi Foundation 2012], CMMI-DEV [SEI 2010], MPT.BR [SOFTEX Recife 2011], MR-MPS-SW [SOFTEX 2012], a norma ISO/IEC 12207 (2008) e o guia PMBOK [PMI 2013].

Essas referências não listam atividades para esse processo, mas descrevem práticas e resultados esperados que podem ser convertidos em atividades de um processo. Além disso, também é possível encontrar frases que sugerem explícita ou implicitamente a existência de uma atividade que contribui para o processo.

Assim, como justificativa para a escolha das atividades que compõem o Processo de Gerência de Riscos de Teste apresentado e demonstrar a relevância e conformidade de cada atividade com as referências que foram utilizadas, foi realizado um mapeamento entre as atividades do processo e tais referências, indicando o quão explícitas as atividades se encontram nos modelos, normas ou guias e a parte do documento que indica a sua existência, caso exista.

O nível de explicitação das atividades nas referências segue a seguinte legenda:

- Explícita: a atividade está relacionada a um tópico da referência;

- Implícita: a atividade está relacionada à referência por meio de uma frase que sugere ou justifica a inclusão da atividade;

- Inexistente: não foi encontrada uma indicação para a atividade na referência.

O mapeamento resumido desse processo encontra-se na Tabela 6, com a indicação do nível de explicitação. O mapeamento completo das atividades, com os trechos onde elas foram encontradas, de forma explícita ou implícita, encontra-se na dissertação disponível no site www.icomp.ufam.edu.br/experts/processosapoio.

Os dados apresentados no mapeamento mostram que todas as atividades presentes no processo especificado estão em conformidade com pelo menos uma das referências citadas. As referências que mais contribuíram justificando as atividades desse processo são, em ordem de relevância, CMMI-DEV, PMBOK, TMMi, ISO/IEC 12207, MR-MPSSW e MPT.BR.

Tabela 6. Mapeamento das Atividades do Processo de Gerência de Riscos de Teste.

\begin{tabular}{|l|c|c|c|c|c|c|}
\hline (Macro)Atividades do processo & $\begin{array}{c}\text { ISO/IEC } \\
\mathbf{1 2 2 0 7}\end{array}$ & CMMI & TMMi & MPS.BR & MPT.BR & PMBOK \\
\hline 1.Planejar Riscos de Teste & Explícita & Explícita & Inexistente & Implícita & Inexistente & Explícita \\
\hline
\end{tabular}




\begin{tabular}{|c|c|c|c|c|c|c|}
\hline 1.1 Definir Categorias de Riscos & Explícita & Explícita & Explícita & Implícita & Inexistente & Implícita \\
\hline $\begin{array}{l}\text { 1.2. Definir Técnicas e Recursos } \\
\text { Necessários para a Identificação } \\
\text { de Riscos de Teste }\end{array}$ & Inexistente & Inexistente & Implícita & Inexistente & Implícita & Explícita \\
\hline $\begin{array}{l}\text { 1.3. Definir Critérios para } \\
\text { Avaliação dos Riscos }\end{array}$ & Inexistente & Explícita & Explícita & Implícita & Inexistente & Implícita \\
\hline $\begin{array}{l}\text { 1.4. Documentar Estratégia de } \\
\text { Gerenciamento de Riscos }\end{array}$ & Implícita & Explícita & Inexistente & Implícita & Inexistente & Explícita \\
\hline $\begin{array}{l}\text { 2. Identificar e Analisar Riscos de } \\
\text { Produto }\end{array}$ & Implícita & Explícita & Explícita & Implícita & Explícita & Explícita \\
\hline 2.1. Identificar Riscos de Produto & Explícita & Explícita & Explícita & Implícita & Implícita & Explícita \\
\hline 2.2: Categorizar Riscos de Produto & Implícita & Explícita & Explícita & Implícita & Inexistente & Explícita \\
\hline 2.3. Avaliar Riscos de Produto & Implícita & Explícita & Explícita & Inexistente & Implícita & Explícita \\
\hline 2.4. Priorizar Riscos de Produto & Inexistente & Explícita & Explícita & Implícita & Inexistente & Implícita \\
\hline $\begin{array}{l}\text { 3. Identificar e Analisar Riscos do } \\
\text { Projeto de Teste }\end{array}$ & Implícita & Explícita & Explícita & Implícita & Explícita & Explícita \\
\hline $\begin{array}{l}\text { 3.1. Identificar Riscos do Projeto } \\
\text { de Teste }\end{array}$ & Explícita & Explícita & Explícita & Implícita & Explícita & Explícita \\
\hline $\begin{array}{l}\text { 3.2. Avaliar Riscos do Projeto de } \\
\text { Teste }\end{array}$ & Implícita & Explícita & Explícita & Inexistente & Implícita & Explícita \\
\hline $\begin{array}{l}\text { 3.3. Categorizar Riscos do Projeto } \\
\text { de Teste }\end{array}$ & Implícita & Explícita & Explícita & Implícita & Inexistente & Explícita \\
\hline $\begin{array}{l}\text { 3.4. Priorizar Riscos do Projeto de } \\
\text { Teste }\end{array}$ & Inexistente & Explícita & Explícita & Implícita & Implícita & Implícita \\
\hline $\begin{array}{l}\text { 4. Definir Ações de Tratamento de } \\
\text { Riscos de Teste }\end{array}$ & Implícita & Explícita & Implícita & Explícita & Implícita & Explícita \\
\hline $\begin{array}{l}\text { 4.1. Desenvolver Plano de } \\
\text { Mitigação para Riscos de Teste }\end{array}$ & Implícita & Explícita & Implícita & Explícita & Implícita & Explícita \\
\hline $\begin{array}{l}\text { 4.2. Desenvolver Plano de } \\
\text { Contingência para Riscos de Teste }\end{array}$ & Inexistente & Explícita & Explícita & Inexistente & Implícita & Explícita \\
\hline 5. Monitorar Riscos de Teste & Explícita & Implícita & Explícita & Explícita & Inexistente & Implícita \\
\hline $\begin{array}{l}\text { 6. Analisar e Registrar Dados de } \\
\text { Riscos de Teste }\end{array}$ & Implícita & Implícita & Implícita & Implícita & Inexistente & Implícita \\
\hline
\end{tabular}

A próxima seção apresenta a representação gráfica e descrição das atividades que compõem o Processo de Gerência de Riscos de Teste, suas dependências, artefatos e papéis associados, dentre outras informações.

\subsection{Representação Gráfica e Descrição do Processo de Gerência de Riscos de Teste}

Este processo é dividido em dois subprocessos: de Planejamento de Riscos de Teste e de Monitoramento e Controle de Riscos de Teste. O processo inicia a partir de uma atividade do Processo de Testes de Software (atividade externa "2. Identificar Riscos"). No entanto, suas atividades são realizadas de forma paralela ao Processo de Testes, permitindo que seus artefatos sejam atualizados sempre que necessário.

O objetivo do primeiro subprocesso é estabelecer o escopo do gerenciamento de riscos a ser realizado durante o processo de teste e todas as informações necessárias para a sua execução, além de prover a documentação dessas informações que servirão de guia para o monitoramento e controle dos riscos. A Figura 3 apresenta a representação gráfica deste subprocesso. 


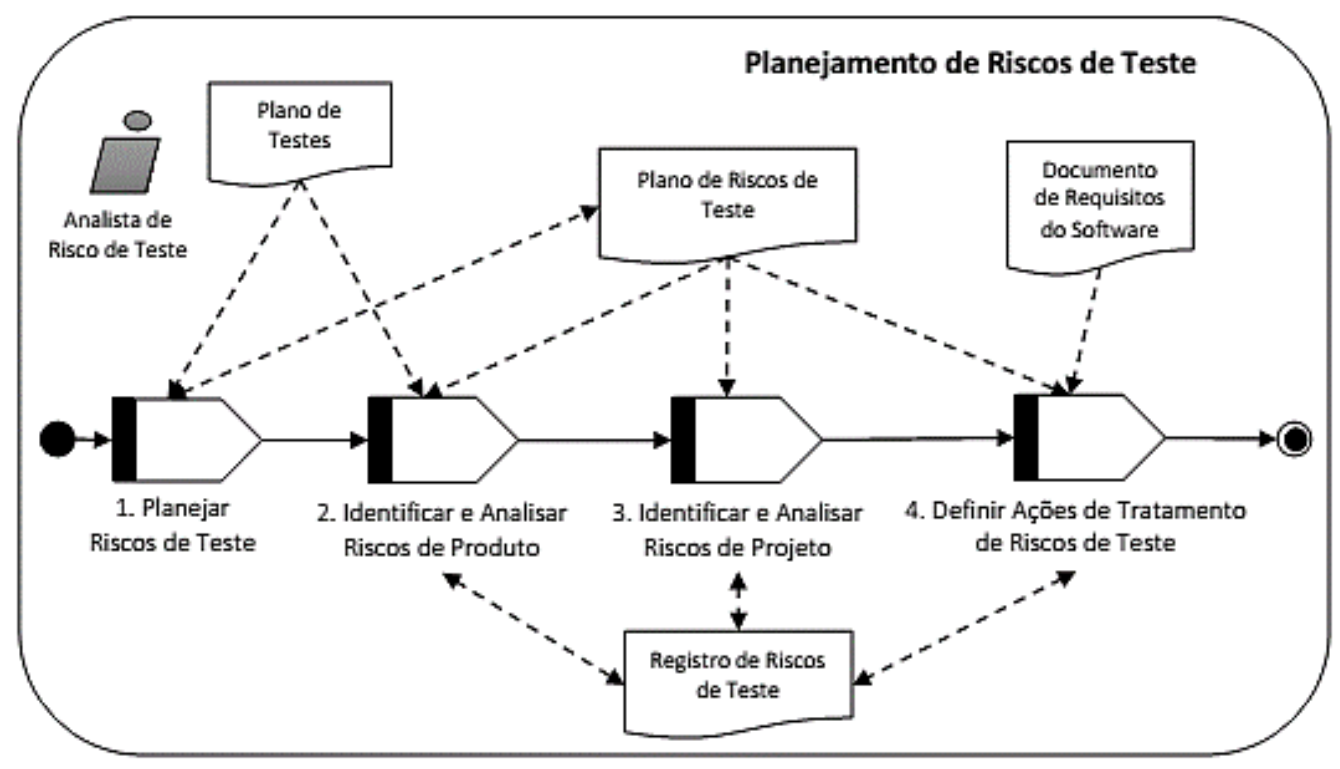

Figura 3. Subprocesso de Planejamento de Riscos de Testes.

A descrição dos processos foi estruturada em um formato que facilitasse a leitura dos gerentes de teste, sendo aceita nos meios acadêmico e industrial. Para isso, utilizouse um conjunto de roteiros para definição dos processos baseado no modelo utilizado pelo grupo de Qualidade de Software da COPPE/UFRJ, propostos em [Villela 2004], com a adaptação de algumas informações necessárias à abordagem utilizada.

Pela complexidade de todo o processo e limitação de espaço, não seria possível apresentar todo o detalhamento do processo proposto. Um exemplo do roteiro utilizado para a definição de atividades dos processos de apoio encontra-se na Tabela 7, onde é descrita a atividade "1.3. Definir Critérios para Avaliação dos Riscos", que faz parte da macroatividade "1. Planejar Riscos de Teste" do Subprocesso de Planejamento de Riscos de Testes (Figura 3). Entre os campos dessa tabela, destaca-se o campo Práticas Sugeridas que consiste em sugestões de práticas/ações com conhecimento adicional que contribuem para a execução do processo, mas que não são de uso obrigatório.

Tabela 7. Instanciação do Roteiro para Definição de Atividades dos Processos de Apoio.

\begin{tabular}{|l|l|}
\hline Atividade: & 1.3. Definir Critérios para Avaliação dos Riscos \\
\hline Descrição: & $\begin{array}{l}\text { Para avaliar os riscos, devem existir critérios para estabelecer a probabilidade } \\
\text { de ocorrência de um risco e o impacto (ou consequência) que ele causará na } \\
\text { qualidade do produto caso ocorra, entre outros atributos adicionais que } \\
\text { diferenciem e representem a severidade de um risco. Além disso, níveis de } \\
\text { classificação de cada atributo precisam ser definidos para que haja uma ordem } \\
\text { de importância coerente. } \\
\text { Os valores dos atributos dos riscos definem a importância deles e podem ser } \\
\text { combinados para se chegar a um valor único para cada risco que será usado } \\
\text { posteriormente para priorizar as ações que devem ser tomadas para mitigar } \\
\text { esses riscos. Os critérios para alocação desses atributos, seus níveis e a forma } \\
\text { como serão combinados devem ser definidos nessa atividade. }\end{array}$ \\
\hline $\begin{array}{l}\text { Critérios de } \\
\text { Entrada: }\end{array}$ & $\begin{array}{l}\text { Ter-se critérios de avaliação de riscos para serem analisados e selecionados } \\
\text { conforme a adequação deles ao contexto do projeto. }\end{array}$ \\
\hline $\begin{array}{l}\text { Critérios de } \\
\text { Saída: }\end{array}$ & $\begin{array}{l}\text { Ter-se os critérios de avaliação dos riscos definidos de acordo com o contexto } \\
\text { do projeto. }\end{array}$ \\
\hline
\end{tabular}




\begin{tabular}{|l|l|}
\hline Responsável: & Analista de Riscos de Teste \\
\hline Participantes: & Analista de Riscos de Teste \\
\hline $\begin{array}{l}\text { Artefatos } \\
\text { Requeridos: }\end{array}$ & Parte do Plano de Teste \\
\hline $\begin{array}{l}\text { Artefatos } \\
\text { Produzidos: }\end{array}$ & Parte do Plano de Riscos de Teste \\
\hline & $\begin{array}{l}\text { Geralmente os critérios são definidos com valores qualitativos como alto, } \\
\text { médio e baixo, ou com números que representem esse valor, como por } \\
\text { exemplo, classificá-los de 1 a 10, onde 1 é o impacto mais alto e 10 é o mais } \\
\text { baixo. Para cada nível de risco, também é recomendável definir limites para } \\
\text { determinar a aceitação ou não de um risco, a priorização ou para definir um } \\
\text { gatilho de ação para a gestão. Por exemplo, limites relacionados a riscos do } \\
\text { cronograma podem ser estabelecidos para envolver a alta administração, } \\
\text { quando os índices de desempenho do cronograma caírem abaixo de 0,95. Para } \\
\text { padronizar a avaliação e reduzir possível subjetividade durante a avaliação, } \\
\text { [Lazic e Mastorakis 2005] sugerem o uso de tabelas de referência de níveis } \\
\text { de probabilidade e de impacto que fornecem um guia para a atribuição dessas } \\
\text { características. Uma forma de combinar os atributos dos riscos associados a } \\
\text { uma função, segundo [Amland 2000], é por meio da Exposição ao Risco que } \\
\text { pode ser expresso pela seguinte equação: } \\
\text { - RE(f) = P(f) * C(f), onde RE(f) é a exposição ao risco da função f, } \\
\text { Pugeridas: é a probabilidade de uma falha ocorrer na função f e C(f) é o } \\
\text { custo ou impacto se uma falha ocorrer na função f. }\end{array}$ \\
\hline $\begin{array}{l}\text { Já em [Chen } \text { et al. 2002], essa mesma equação é usada, porém, a Exposição } \\
\text { ao Risco é calculada em função de casos de testes (t). }\end{array}$ \\
\hline
\end{tabular}

O segundo subprocesso (Figura 4) tem como objetivo executar as instruções definidas no Plano de Riscos de Teste para monitorar os riscos identificados e realizar as ações especificadas no plano para o controle dos riscos quando aplicável, além de documentar o que for feito no decorrer deste subprocesso.

Novamente, será apresentado apenas um exemplo de detalhamento de atividade deste subprocesso. Assim, na Tabela 8 é apresentada uma atividade como exemplo para o Subprocesso de Monitoramento e Controle de Riscos de Testes: Analisar e Registrar Dados de Riscos de Teste.

As principais diferenças entre o processo de gerência de riscos apresentado e um processo de gerência de riscos geral estão relacionadas a fatores como o tratamento que é dado aos riscos e ao momento em que eles são identificados e tratados. No processo adaptado para o contexto de teste, os riscos começam a ser identificados durante as primeiras atividades do processo de testes para que possa contribuir com o planejamento dos testes, ajudando por exemplo, a priorizar os casos de testes que possuam riscos mais críticos associados.

Além dessas diferenças, o processo especificado nesse capítulo contém informações sobre a gerência dos riscos adaptadas para o contexto de testes, dando exemplos de riscos que podem ser encontrados nesse cenário, exemplos de tratamento dos riscos e também possui práticas para executar as atividades no cenário de testes coletadas a partir de modelos e padrões de qualidade de software e de artigos científicos relacionados com uso da gerência de riscos nesse cenário. 


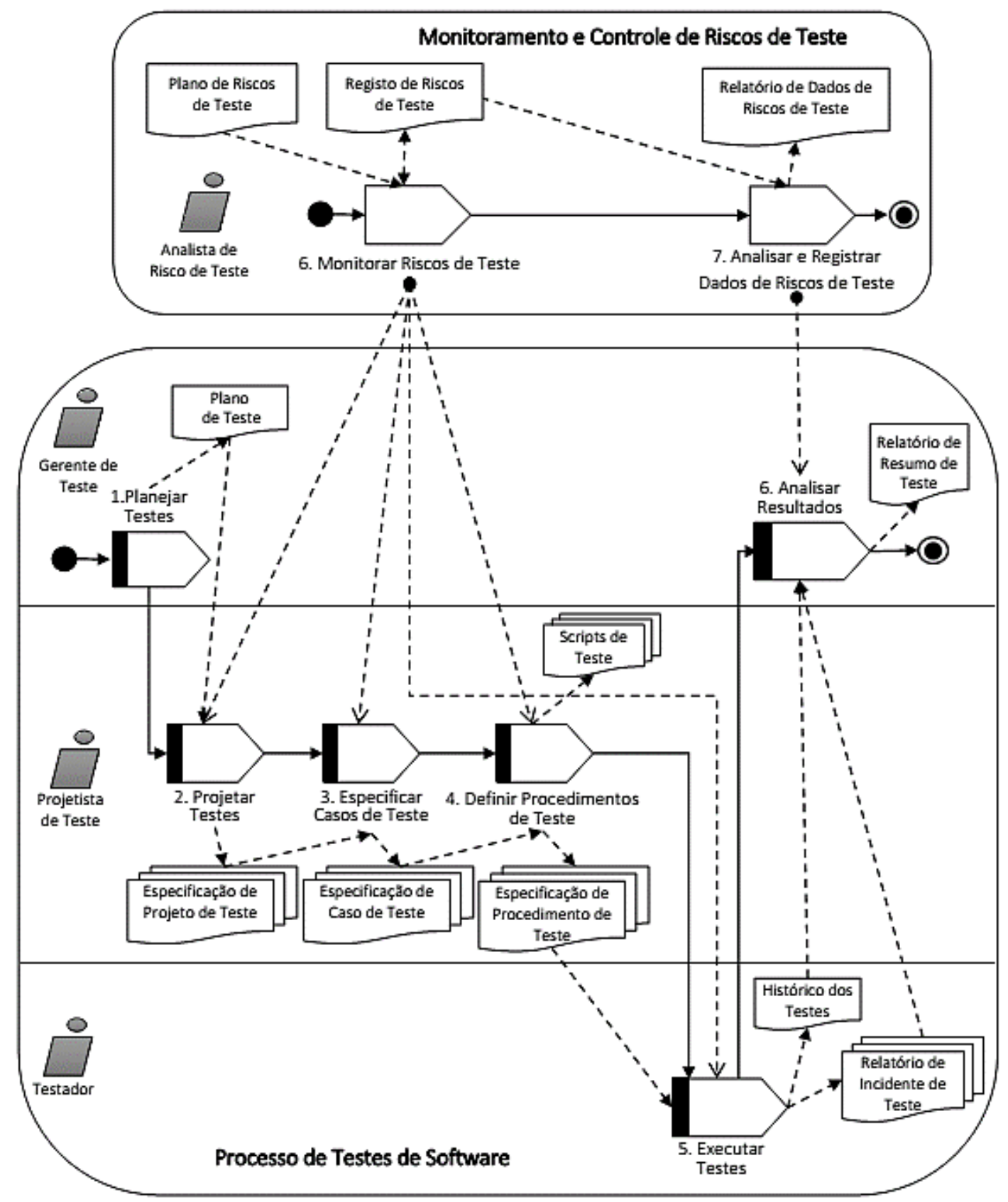

Figura 4. Subprocesso de Monitoramento e Controle de Riscos de Testes.

Tabela 8. Exemplo de Atividade do Subprocesso de Monitoramento e Controle de Riscos de Testes.

\begin{tabular}{|l|l|}
\hline Atividade: & 6. Analisar e Registrar Dados de Riscos de Teste \\
\hline Descrição: & $\begin{array}{l}\text { As informações coletadas em relação aos riscos, como métricas, status, riscos } \\
\text { mitigados, etc., devem ser analisadas para verificar o nível de risco restante e serem } \\
\text { repassadas ao Gerente/Líder de Teste e stakeholders para que eles possam decidir se o } \\
\text { nível de risco é aceitável e tomarem as aços cabíveis de acordo com a estratégia de } \\
\text { gerência de riscos e estratégia de testes definida. } \\
\text { Além disso, essas informações devem ser documentadas no documento Relatório de } \\
\text { Dados de Riscos e anexado ao documento Relatório de Resumo de Teste do projeto, } \\
\text { para servir de apoio a futuros planos de gerenciamento de risco que tenham escopo } \\
\text { semelhante ao do projeto. }\end{array}$ \\
\hline $\begin{array}{l}\text { Critérios de } \\
\text { Entrada: }\end{array}$ & Ter-se os riscos monitorados e dados sobre eles coletados. \\
\hline
\end{tabular}




\begin{tabular}{|l|l|}
\hline $\begin{array}{l}\text { Critérios de } \\
\text { Saída: }\end{array}$ & Ter-se os dados sobre os riscos analisados e documentados. \\
\hline Responsável: & Analista de Riscos de Teste \\
\hline Participantes: & $\begin{array}{l}\text { Analista de Riscos de Teste, Líder de Teste (opcional - caso não exista Gerente de } \\
\text { Teste e o Gerente de Projeto esteja no lugar no Analista) e outros stakeholders } \\
\text { envolvidos. }\end{array}$ \\
\hline $\begin{array}{l}\text { Artefatos } \\
\text { Requeridos: }\end{array}$ & Plano de Riscos de Teste e Registro de Riscos de Teste \\
\hline $\begin{array}{l}\text { Artefatos } \\
\text { Produzidos: }\end{array}$ & Relatório de Dados de Riscos de Teste, anexo do Relatório de Resumo de Teste \\
\hline $\begin{array}{l}\text { Práticas } \\
\text { Sugeridas: }\end{array}$ & $\begin{array}{l}\text { Em [Stoelinga e Timmer 2009], é apresentado um método para calcular o risco de um } \\
\text { sistema depois de passar com sucesso por uma suíte de testes. Primeiro, é estimado o } \\
\text { número de falhas que ainda restam e não foram detectadas pelos testes, depois é } \\
\text { definido o risco restante do sistema por meio da gravidade das falhas esperadas. }\end{array}$ \\
\hline
\end{tabular}

A próxima seção irá apresentar o segundo processo de apoio proposto nessa pesquisa: o Processo de Gerência de Recursos Humanos aplicados ao Processo de Testes.

\section{Processo de Gerência de Recursos Humanos de Teste}

Todo processo de teste necessita de recursos humanos devidamente alocados aos projetos de teste com habilidades específicas, de acordo com as características de cada projeto e dos tipos de teste a serem aplicados, e que estejam disponíveis para exercer suas funções no tempo que for determinado.

O processo de Gerência de Recursos Humanos de Teste ajuda a identificar quais habilidades são necessárias e a selecionar os recursos disponíveis. Além disso, este processo também ajuda a coordenar atividades referentes a treinamentos e contratações de recursos, caso não haja recursos disponíveis no quadro de funcionários ou se eles não possuírem as habilidades requeridas para o projeto.

\subsection{Papéis e Artefatos do Processo de Gerência de Recursos Humanos de Teste}

O papel responsável pelo processo é o de Gerente de Recursos Humanos, que deve definir as necessidades relacionadas aos recursos humanos requeridos para o projeto de teste e prover treinamento e/ou recrutamento adequado para atender às necessidades do projeto. $\mathrm{Na}$ ausência de um profissional dedicado a este papel, o Gerente de Teste pode executar as atividades deste processo por ter um conhecimento mais abrangente com relação ao processo de teste e aos projetos de teste que são realizados.

Os artefatos gerados pelo processo são:

- Plano de Recursos Humanos de Teste, onde são especificados os recursos humanos requeridos para a realização dos testes, os papéis, as responsabilidades e os conhecimentos necessários, além dos planos de treinamento e contratação;

- Repositório de Recursos Humanos de Teste, com dados a respeito dos recursos humanos de teste, como habilidades, papéis, características comportamentais e profissionais, projetos trabalhados, disponibilizando informações necessárias para uma alocação efetiva destes recursos em um novo projeto.

\subsection{Extração das Atividades do Processo de Gerência de Riscos de Teste}

De forma análoga ao que foi feito para o processo de apoio anterior e com o mesmo objetivo, também foi estabelecido um mapeamento entre as atividades do Processo de Gerência de Recursos Humanos de Teste e as referências utilizadas para a escolha das atividades que compõem o seu processo. Nesse processo foram utilizadas como principais referências os modelos TMMi [TMMi Foundation 2012], MPT.BR [SOFTEX Recife 
2011], MR-MPS-SW [SOFTEX 2012], a norma ISO/IEC 12207 (2008) e o guia PMBOK [PMI 2013].

O mapeamento resumido desse processo encontra-se na Tabela 9 com a legenda do nível de explicitação. O mapeamento completo das atividades, com os trechos onde elas foram encontradas, de forma explícita ou implícita, encontra-se na dissertação disponível no site www.icomp.ufam.edu.br/experts/processosapoio.

\section{Tabela 9. Mapeamento resumido das atividades do Processo de Gerência de Recursos Humanos de Teste.}

\begin{tabular}{|c|c|c|c|c|c|}
\hline (Macro)Atividades do processo & $\begin{array}{l}\text { ISO/IEC } \\
12207\end{array}$ & TMMi & MPS.BR & MPT.BR & PMBOK \\
\hline 1. Planejar Recursos Humanos de Teste & Inexistente & Inexistente & Implícita & Explícita & Explícita \\
\hline $\begin{array}{l}\text { 1.1. Identificar Requisitos da Equipe de } \\
\text { Teste }\end{array}$ & Explícita & Implícita & Implícita & Implícita & Implícita \\
\hline 1.2. Definir Métodos de Avaliação & Explícita & Inexistente & Explícita & Inexistente & Implícita \\
\hline 1.3. Alocar Recursos & Implícita & Explícita & Explícita & Inexistente & Explícita \\
\hline 2. Planejar Obtenção de Conhecimento & Implícita & Explícita & Implícita & Implícita & Implícita \\
\hline $\begin{array}{l}\text { 2.1. Verificar Necessidade de } \\
\text { Treinamento/Contratação }\end{array}$ & Inexistente & Explícita & Explícita & Implícita & Inexistente \\
\hline $\begin{array}{l}\text { 2.2. Planejar e Executar Treinamentos } \\
\text { (opcional) }\end{array}$ & Explícita & Explícita & Explícita & Explícita & Explícita \\
\hline $\begin{array}{l}\text { 2.3. Planejar e Executar Contratações } \\
\text { (opcional) }\end{array}$ & Implícita & Explícita & Inexistente & Explícita & Implícita \\
\hline 3. Avaliar Desempenho da Equipe de Teste & Explícita & Inexistente & Implícita & Inexistente & Implícita \\
\hline $\begin{array}{l}\text { 4. Atualizar Repositório de Recursos } \\
\text { Humanos de Teste }\end{array}$ & Explícita & Inexistente & Inexistente & Inexistente & Inexistente \\
\hline
\end{tabular}

Segundo os dados do mapeamento, todas as atividades presentes no processo especificado também estão em conformidade com pelo menos uma das referências citadas. As referências que mais contribuíram justificando as atividades desse processo são, em ordem de relevância, ISO/IEC 12207, MR-MPS-SW, PMBOK, TMMi TMMi e MPT.BR.

A próxima seção apresenta a representação gráfica e descrição das atividades que compõem o Processo de Gerência de Recursos Humanos de Teste, suas dependências, artefatos e papéis associados, dentre outras informações.

\subsection{Representação Gráfica e Descrição do Processo de Gerência de Recursos Humanos de Teste}

A Figura 5 apresenta o modelo do Processo de Gerência de Recursos Humanos de Teste. Este processo atua durante a macroatividade 1 do Processo de Teste de Software (Figura 2) e se relaciona de forma similar ao outro processo de apoio. Ao iniciar a subatividade "4. Planejar Recursos Humanos do Processo de Teste", a macroatividade "1. Planejar Recursos Humanos de Teste" é executada e o "Plano de Recursos Humanos de Teste" é gerado. Ao iniciar a subatividade "8. Especificar Necessidade de Treinamento", é executada a macroatividade " 2 . Planejar Obtenção de Conhecimento". Ao concluir, o Processo de Teste volta a seguir seu fluxo e as próximas atividades do processo de apoio são realizadas em paralelo ao longo do Processo de Teste. 


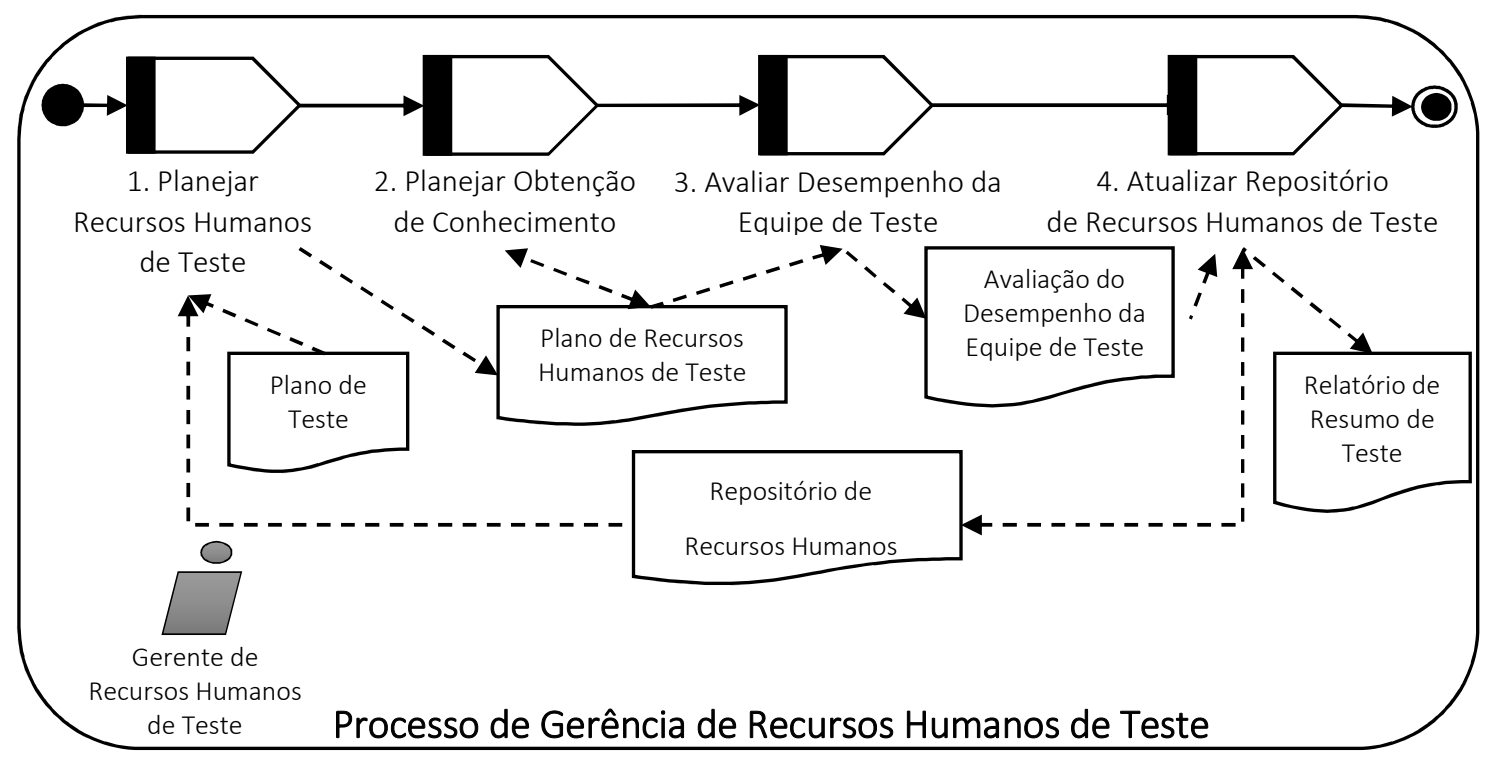

Figura 5. Processo de Gerência de Recursos Humanos de Teste.

Na Tabela 10 é apresentada uma atividade como exemplo para o Processo de Gerência de Recursos Humanos de Testes. Esta atividade faz parte da macroatividade " 1. Planejar Recursos Humanos de Teste".

As principais diferenças entre o processo de gerência de recursos humanos aplicado ao processo de testes de software apresentado nesse artigo e um processo de gerência de recursos humanos geral estão relacionadas com a definição e adaptação das atividades que são fundamentais para a gerência desses recursos durante o processo de testes. Na definição detalhada desse processo são especificados, por exemplo, fatores que devem ser levados em conta ao alocar recursos humanos de testes e ao planejar treinamentos e contratações para os perfis de testes. A especificação desses fatores voltados para o cenário de testes e a definição de práticas sugeridas para a realização das atividades pode ajudar a entender e conduzir essas atividades de forma mais rápida do que tentar seguir um processo mais genérico.

Por fim, considerando que as atividades de testes costumam estar entre as últimas atividades do ciclo de desenvolvimento de um software, problemas relacionados à indisponibilidade de recursos ou recursos incapacitados para exercer tais atividades podem comprometer bastante o resultado dos testes e, consequentemente, o sucesso de um projeto de software. Por isso, esse processo é de suma importância para os testes, uma vez que a gerência dos recursos humanos impacta diretamente na qualidade do processo de testes.

As principais diferenças entre o processo de gerência de recursos humanos apresentado nesse capítulo e um processo de gerência de recursos humanos geral estão relacionadas com a definição e adaptação das atividades que são fundamentais para a gerência desses recursos durante o processo de testes. Na definição desse processo são especificados, por exemplo, fatores que devem ser levados em conta ao alocar recursos humanos de testes e ao planejar treinamentos e contratações para os perfis de testes. A especificação desses fatores voltados para o cenário de testes e a definição de práticas sugeridas para a realização das atividades pode ajudar a entender e conduzir essas atividades de forma mais rápida do que tentar seguir um processo mais genérico. 
Tabela 10. Exemplo de Atividade do Processo de Gerência de Recursos Humanos de Testes.

\begin{tabular}{|c|c|}
\hline Atividade: & 1.3. Alocar Recursos \\
\hline Descrição: & $\begin{array}{l}\text { A partir do Repositório de Recursos Humanos de Teste e dos requisitos da equipe de } \\
\text { teste identificados na Atividade } 1.1 \text {, o Gerente de Recursos Humanos verifica quais } \\
\text { profissionais atendem às especificações requeridas para o projeto e determina quem } \\
\text { fará parte da equipe de teste. } \\
\text { O resultado dessa decisão é documentado no Plano de Teste do projeto. } \\
\text { Nota: considerando que o processo é interativo, caso seja necessário substituir, incluir } \\
\text { ou excluir recursos, esta atividade pode ser executada novamente a qualquer } \\
\text { momento. }\end{array}$ \\
\hline $\begin{array}{l}\text { Critérios de } \\
\text { Entrada: }\end{array}$ & $\begin{array}{l}\text { Ter-se uma lista de recursos disponíveis a serem analisados e selecionados, além de } \\
\text { critérios de seleção predefinidos. }\end{array}$ \\
\hline $\begin{array}{l}\text { Critérios de } \\
\text { Saída: }\end{array}$ & Ter-se alocado os recursos humanos necessários para o projeto de teste. \\
\hline Responsável: & Gerente de Recursos Humanos de Teste \\
\hline Participantes: & Gerente de Recursos Humanos de Teste \\
\hline $\begin{array}{l}\text { Artefatos } \\
\text { Requeridos: }\end{array}$ & Plano de Recursos Humanos de Teste, Repositório de Recursos Humanos de Teste \\
\hline $\begin{array}{l}\text { Artefatos } \\
\text { Produzidos: }\end{array}$ & $\begin{array}{l}\text { Parte do Plano de Recursos Humanos de Teste, Repositório de Recursos Humanos } \\
\text { atualizado. }\end{array}$ \\
\hline $\begin{array}{l}\text { Práticas } \\
\text { Sugeridas: }\end{array}$ & $\begin{array}{l}\text { Critérios de seleção e a prioridade entre eles podem ser definidos para auxiliar na } \\
\text { alocação dos recursos. Alguns exemplos de critérios são [PMI 2013]: } \\
\text { - Disponibilidade: identifique se o membro da equipe está disponível para } \\
\text { trabalhar no projeto durante o período de tempo necessário. } \\
\text { - Custo: verifique se o custo de adicionar o membro da equipe está dentro do } \\
\text { orçamento previsto. } \\
\text { - Experiência: verifique se o membro da equipe tem experiência relevante que } \\
\text { contribuirá para o sucesso do projeto. } \\
\text { - Competência: verifique se o membro da equipe tem as competências } \\
\text { necessárias para o projeto. } \\
\text { - Conhecimento: considere se o membro da equipe tem conhecimento } \\
\text { relevante do cliente, projetos implementados semelhantes e nuances do } \\
\text { ambiente de projeto. } \\
\text { - Habilidade: determine se o membro tem as habilidades suficientes para } \\
\text { utilizar as ferramentas do projeto. } \\
\text { Atitude: determine se o membro tem a capacidade de trabalhar com os } \\
\text { outros como uma equipe coesa. } \\
\text { Fatores internacionais: considere equipe local do membro, fuso horário e } \\
\text { capacidade de comunicação. }\end{array}$ \\
\hline
\end{tabular}

Por fim, considerando que as atividades de testes costumam estar entre as últimas atividades do ciclo de desenvolvimento de um software, problemas relacionados à indisponibilidade de recursos ou recursos incapacitados para exercer tais atividades podem comprometer bastante o resultado dos testes. Por isso, o processo definido é de suma importância para os testes, uma vez que a gerência dos recursos humanos impacta diretamente na qualidade do processo de testes.

Na próxima seção é apresentada uma avaliação dos processos propostos nesse trabalho, realizadas por especialistas por meio de uma revisão por pares.

\section{Avaliação dos Processos de Apoio}

A avaliação dos processos de apoio definidos nesta pesquisa foi feita por um conjunto de especialistas utilizando a técnica de Revisão por Pares, que busca identificar defeitos e sugerir correções ou recomendar mudanças nos componentes revisados [SEI 2010]. Este estudo foi conduzido com o objetivo de avaliar se os processos de apoio especificados 
neste trabalho estavam adequados para atender às necessidades do processo de testes, sob o ponto de vista de pesquisadores e profissionais com experiência nas áreas de conhecimento dos processos de apoio (riscos e recursos humanos) e de teste de software.

\subsection{Planejamento da Revisão por Pares}

A revisão foi planejada com base em dois focos de avaliação, seguindo o modelo de avaliação de processos de software adotado em [Barcellos 2009]:

- Foco na forma: avalia se todos os componentes necessários para execução de um processo foram especificados e estão definidos corretamente, e;

- Foco no conteúdo: avalia se os componentes do processo e o seu conteúdo são adequados para a execução do processo, e se a instanciação dele ao processo de testes foi realizada adequadamente.

Para isto, foram definidos cinco perfis de conhecimento para avaliação dos processos propostos:

- Perfil de Definição/Avaliação de Processos de Software (DAPS) (foco na forma). Avaliaram a estrutura dos processos na sua especificação e em seus diagramas, verificando se estavam bem definidos;

- Perfil de Gerência de Recursos Humanos (GRH) (foco no conteúdo). Avaliaram se as informações referentes ao Processo de Recursos Humanos de Teste estavam adequadas em relação às práticas da gerência de recursos humanos;

- Perfil de Gerência de Riscos (GRI) (foco no conteúdo). Avaliaram se as informações referentes ao Processo de Riscos de Teste estavam adequadas em relação às práticas da gerência de riscos;

- Perfil de Processo de Testes - Academia (PTA) (foco no conteúdo). Avaliaram se os processos de apoio foram adaptados de acordo com as necessidades existentes no cenário de teste, levando em consideração a experiência como profissional na área de testes, e;

- Perfil de Processo de Testes - Indústria (PTI) (foco no conteúdo). Avaliaram se os processos de apoio foram adaptados de acordo com as necessidades existentes no cenário de teste, levando em consideração a experiência como pesquisador na área de testes.

Para a condução desta revisão, foram desenvolvidos dois checklists (um para cada foco de avaliação), a fim de que alguns critérios básicos de avaliação fossem considerados pelos revisores. A Figura 6 apresenta uma parte do checklist de revisão por pares com foco na forma. 


\begin{tabular}{|c|c|c|c|}
\hline ID & Questão & Sim & Não \\
\hline & Diagramas X Especificação do processo & & \\
\hline Q01 & $\begin{array}{l}\text { A notação utilizada no processo representa claramente o significado de cada item (exemplo: } \\
\text { macro-atividade|, artefato, papel) do processo? }\end{array}$ & & \\
\hline Q02 & As conexões e os tipos de conexões entre os elementos do processo estão adequados? & & \\
\hline Q03 & $\begin{array}{l}\text { O modelo do processo corresponde à sua especificação em relação à sequência de atividades, } \\
\text { artefatos, papéis e interações entre processos? }\end{array}$ & & \\
\hline Q04 & $\begin{array}{l}\text { O fluxo do processo possui uma sequência lógica que possibilite segui-lo até o fim (última macro- } \\
\text { atividade)? }\end{array}$ & & \\
\hline \multirow[t]{2}{*}{ Q05 } & $\begin{array}{l}\text { Os pontos de interseção entre os processos de apoio e o processo de teste são claros e facilmente } \\
\text { mapeados na descrição de cada processo (o de apoio e o de teste)? }\end{array}$ & & \\
\hline & Papéis & & \\
\hline Q06 & $\begin{array}{l}\text { O nome dos papéis está em conformidade com sua descrição e às suas funções no processo de } \\
\text { apoio? }\end{array}$ & & \\
\hline Q07 & A descrição dos papéis foi definida e está claramente descrita? & & \\
\hline \multirow[t]{2}{*}{ Q08 } & Todos os papéis envolvidos de cada atividade são descritos e foram previamente definidos? & & \\
\hline & Artefatos & & \\
\hline Q09 & O nome dos artefatos é claro e representa seu conteúdo? & & \\
\hline Q10 & A descrição dos artefatos foi definida e está claramente descrita? & & \\
\hline
\end{tabular}

Figura 6. Fragmento do Checklist de Revisão com Foco na Forma.

Ainda foi desenvolvida uma planilha de resposta (Figura 7) adaptada de [Barcellos 2009], onde os especialistas deveriam incluir seus comentários e sugestões de correção, além da classificação dos comentários nas seguintes categorias:

- TA (Técnico Alto), se foi encontrado um problema em um item que, se não for alterado, comprometerá a definição final do processo de apoio;

- TB (Técnico Baixo), se foi encontrado um problema em um item que seria conveniente alterar;

- E (Edição), se foi encontrado erro de português ou possíveis melhorias no texto;

- Q (Questionamento), se houve dúvidas em relação ao conteúdo do processo;

- $\mathrm{G}$ (Geral), se o comentário for geral.

\begin{tabular}{|c|c|c|c|c|c|c|c|}
\hline \multicolumn{8}{|c|}{ Planilha de Resposta da Revisão por Pares } \\
\hline \multicolumn{8}{|c|}{$\begin{array}{l}\text { Instruções } \\
\text { 1. Leia a especificação e diagramas do(s) processo(s) de apoio e templates relacionados, analisando se o conteúdo deles contribui para a definição } \\
\text { deste(s) processo(s) de apoio no contexto do processo de teste. } \\
\text { 2. Leia também as influências do(s) processo(s) de apoio presentes em algumas atividades do Processo de Teste enviado em anexo e analise se elas } \\
\text { interferem corretamente no Processo de Teste contribuindo para a execução do(s) processo(s) de apoio. } \\
\text { 3. Durante a leitura, utilize o Checklist de Revisão por Pares para guiar na observação de pontos essenciais para esta pesquisa. } \\
\text { 4. Ao identificar pontos para os quais deseja registrar um comentário, seja relacionado ao checklist ou não, utilize esta planilha para registrar os } \\
\text { comentários. As instruçốes para preenchimento da planilha podem ser obtidas clicando nas células da planilha cujo canto superior direito está } \\
\text { identificado em vermelho. } \\
\text { 5. Ao concluir sua revisão, por favor, envie este documento para o email }\end{array}$} \\
\hline \multicolumn{8}{|c|}{ Revisor: } \\
\hline \multicolumn{8}{|c|}{ Planilha de Resposta da Revisão por Pares } \\
\hline ID & Documento revisado & Processo & $\begin{array}{c}\text { Categoria } \\
\text { (TA, TB, E, } \\
\text { Q G) }\end{array}$ & $\begin{array}{l}\text { ID da Questão } \\
\text { (se aplicável) }\end{array}$ & Descrição do Item & $\begin{array}{l}\text { Resposta/Comentário com a } \\
\text { Justificativa }\end{array}$ & Esboço de Ação Corretiva \\
\hline & & & & & & & \\
\hline & & & & & & & \\
\hline & & & & & & & \\
\hline
\end{tabular}

Figura 7. Planilha de Resposta da Revisão por Pares.

O material completo elaborado para a revisão foi composto pelos documentos a serem revisados, documentos de apoio à execução da revisão, um documento que explicou a estrutura do conteúdo a ser revisado e os questionários de caracterização dos avaliadores.

Os documentos que compuseram o pacote do estudo foram: 
1. Os diagramas dos processos de apoio e de teste;

2. A especificação do Processo de Gerência de Recursos Humanos de Teste;

3. A especificação do Processo de Gerência de Riscos de Teste;

4. A especificação do Processo de Testes utilizado;

5. Os templates dos artefatos dos processos de apoio.

Os documentos de apoio à execução da revisão são:

6. O Checklist de revisão por pares com foco na forma;

7. O Checklist de revisão por pares com foco no conteúdo;

8. A planilha para registrar respostas do checklist e demais comentários;

O documento que explica a estrutura do conteúdo a ser revisado:

9. A notação utilizada para construção dos diagramas e os roteiros de descrição dos processos.

Os questionários de caracterização dos avaliadores:

10. Questionário de Caracterização - Perfil de Definição/Avaliação de Processos de Software;

11. Questionário de Caracterização - Perfil de Gerência de Recursos Humanos;

12. Questionário de Caracterização - Perfil de Gerência de Riscos;

13. Questionário de Caracterização - Perfil de Processo de Testes (Academia e Indústria).

O material da revisão foi dividido de acordo com o foco e o conhecimento de cada perfil, conforme mostra a Tabela 11 a seguir.

Tabela 11. Distribuição do material da revisão de acordo com o perfil do revisor.

\begin{tabular}{|c|c|l|}
\hline Perfil & \multicolumn{1}{|c|}{$\begin{array}{c}\text { Documentos } \\
\text { recebidos }\end{array}$} & \multicolumn{1}{c|}{ Observações } \\
\hline DAPS & $1,2,3,5,6,8,9$ e 10 & $\begin{array}{l}\text { O processo de testes de software não faz parte, pois } \\
\text { avaliar sua estrutura (foco na forma) não era um objetivo } \\
\text { dessa revisão. }\end{array}$ \\
\hline GRH & $1,2,4,5,7,8,9,11$ & $\begin{array}{l}\text { 1: sem os diagramas do processo de gerência de riscos; 5: } \\
\text { apenas dos artefatos desse processo. }\end{array}$ \\
\hline GRI & $1,2,4,5,7,8,9,12$ & $\begin{array}{l}\text { 1: sem os diagramas do processo de gerência de recursos } \\
\text { humanos; 5: apenas dos artefatos desse processo. }\end{array}$ \\
\hline $\begin{array}{c}\text { PTA e } \\
\text { PTI }\end{array}$ & $1,2,3,4,5,7,8,9$ e 13 & $\begin{array}{l}\text { Era preciso revisar tudo do ponto de vista do profissional } \\
\text { e do pesquisador de Teste. }\end{array}$ \\
\hline
\end{tabular}

\subsection{Execução da Revisão por Pares}

Conforme a definição desses perfis, foi selecionado 1 revisor para cada perfil de conhecimento definido, totalizando 5 revisores. Apesar de ser um baixo número, em revisões de pares aplicados a processos de software é uma amostra representativa, por contar com todos os perfis de revisores planejados para o estudo. Assim, um e-mail foi enviado a cada revisor, no final de maio/2014, convidando-os para participar da revisão, explicando o que seria avaliado e o tempo estimado para a conclusão. Todos confirmaram a participação e então foi enviado o questionário de caracterização com o objetivo apenas de detalhar o nível de conhecimento dos revisores. Logo em seguida, foi enviado um email com o objetivo e o foco da revisão de acordo com o perfil do avaliador, as instruções a serem seguidas e o material da revisão. As revisões ocorreram até o fim do mês de Julho/2014. 
Os dados da Tabela 12 apresentam a experiência de cada participante do estudo, conforme os dados respondidos nos questionários.

Tabela 12. Caracterização dos Revisores por Perfil de Conhecimento.

\begin{tabular}{|c|c|c|c|c|c|}
\hline \multirow{2}{*}{ Item de caracterização } & \multicolumn{5}{|c|}{ Revisor } \\
\hline & DAPS & GRI & GRH & PTI & PTA \\
\hline Formação acadêmica & Doutor & Doutor & Doutor & Mestre & Doutor \\
\hline $\begin{array}{l}\text { Nível/Anos de Experiência em } \\
\text { Definição de Processos de SW }\end{array}$ & $\begin{array}{l}\text { Alto / } \\
14 \text { anos }\end{array}$ & $\begin{array}{l}\text { Alto / } \\
15 \text { anos }\end{array}$ & $\begin{array}{l}\text { Médio / } \\
5 \text { anos }\end{array}$ & $\begin{array}{l}\text { Alto / } \\
6 \text { anos }\end{array}$ & $\begin{array}{l}\text { Médio / } \\
10 \text { anos }\end{array}$ \\
\hline $\begin{array}{l}\text { Nível/Anos de Experiência em } \\
\text { Avaliação de Processos de SW }\end{array}$ & $\begin{array}{l}\text { Alto / } 13 \\
\text { anos }\end{array}$ & Alto / 7 anos & $\begin{array}{l}\text { Médio / } 5 \\
\text { anos }\end{array}$ & $\begin{array}{c}\text { Alto / } 4 \\
\text { anos }\end{array}$ & $\begin{array}{l}\text { Baixo / } 10 \\
\text { anos }\end{array}$ \\
\hline $\begin{array}{l}\text { Nível/Anos de Experiência em } \\
\text { Processo de Gerência de Riscos }\end{array}$ & $\begin{array}{l}\text { Não se } \\
\text { aplica. }\end{array}$ & $\begin{array}{l}\text { Alto / } 10 \\
\text { anos }\end{array}$ & $\begin{array}{l}\text { Não se } \\
\text { aplica. }\end{array}$ & $\begin{array}{c}\text { Médio / } 3 \\
\text { anos }\end{array}$ & $\begin{array}{l}\text { Baixo / } 8 \\
\text { anos }\end{array}$ \\
\hline $\begin{array}{l}\text { Nível/Anos de Experiência em } \\
\text { Processo de Gerência de RH }\end{array}$ & $\begin{array}{l}\text { Não se } \\
\text { aplica. }\end{array}$ & $\begin{array}{l}\text { Não se } \\
\text { aplica. }\end{array}$ & $\begin{array}{l}\text { Médio / } 5 \\
\text { anos }\end{array}$ & $\begin{array}{l}\text { Médio / } 3 \\
\text { anos }\end{array}$ & Nenhum \\
\hline $\begin{array}{l}\text { Nível/Anos de Experiência em } \\
\text { Processo de Testes de Software }\end{array}$ & $\begin{array}{l}\text { Médio / } 5 \\
\text { anos }\end{array}$ & $\begin{array}{l}\text { Médio / } 10 \\
\text { anos }\end{array}$ & $\begin{array}{l}\text { Médio / } 5 \\
\text { anos }\end{array}$ & $\begin{array}{c}\text { Alto / } 6 \\
\text { anos }\end{array}$ & $\begin{array}{l}\text { Alto / } 10 \\
\text { anos }\end{array}$ \\
\hline $\begin{array}{l}\text { Normas, modelos ou guia para } \\
\text { melhoria do processo de } \\
\text { software e do processo de } \\
\text { testes que } \\
\text { conhecimento }\end{array}$ & $\begin{array}{c}\text { CMMI, } \\
\text { MPS.BR, } \\
\text { PMBOK, } \\
\text { ISO/IEC 12207, } \\
\text { ISO/IEC 15504 }\end{array}$ & $\begin{array}{c}\text { CMMI, } \\
\text { MPS.BR, } \\
\text { PMBOK, } \\
\text { ISO/IEC 12207, } \\
\text { ISO/IEC 15504 }\end{array}$ & $\begin{array}{c}\text { CMMI, } \\
\text { MPS.BR, } \\
\text { PMBOK, } \\
\text { ISO/IEC } \\
\text { 12207, } \\
\text { ISO/IEC } \\
15504\end{array}$ & $\begin{array}{l}\text { CMMI, } \\
\text { PMBOK, } \\
\text { TMMi, } \\
\text { ISO/IEC } \\
15504\end{array}$ & $\begin{array}{c}\text { CMMI, } \\
\text { MPS.BR, } \\
\text { PMBOK, } \\
\text { MPT.BR, } \\
\text { ISO/IEC } \\
12207\end{array}$ \\
\hline $\begin{array}{l}\text { Certificações de teste que } \\
\text { possui }\end{array}$ & Não se aplica. & Não se aplica. & $\begin{array}{l}\text { Não se } \\
\text { aplica. }\end{array}$ & $\begin{array}{c}\text { ISTQB: } \\
\text { CTFL, } \\
\text { CTAL-TM }\end{array}$ & $\begin{array}{c}\text { ISTQB: } \\
\text { CTFL }\end{array}$ \\
\hline
\end{tabular}

O objetivo de aplicar esses questionários não era avaliar se o revisor estava apto para participar da revisão e sim conhecer de forma mais detalhada a experiência dele para descrever seu nível de conhecimento no relato dessa revisão. Assim, foi possível descrever o nível de experiência de cada revisor nos domínios para os quais ele foi direcionado na revisão.

\subsection{Análise dos Resultados da Revisão por Pares}

A análise da revisão foi feita a partir da contagem das observações (questionamentos) e da decisão tomada em resposta às observações realizadas para cada revisor. Como resultado da execução da revisão, foram retornadas observações analisadas e categorizadas em: NA, se a observação não foi atendida; PA, se a observação foi parcialmente atendida; e A, se a observação foi atendida. A Tabela 13 apresenta estes resultados.

Tabela 13. Quantidade de Observações por Revisor e por Resultado da Análise.

\begin{tabular}{|c|c|c|c|c|}
\hline \multirow{2}{*}{ Revisor } & \multicolumn{3}{|c|}{ Decisão após Análise } & \multirow{2}{*}{$\begin{array}{c}\text { Total por } \\
\text { Revisor }\end{array}$} \\
\cline { 2 - 4 } & NA & PA & A & $\mathbf{1 5}$ \\
\hline DAPS & 0 & 0 & 15 & $\mathbf{2 6}$ \\
\hline GRH & 15 & 2 & 9 & $\mathbf{2 8}$ \\
\hline GRI & 8 & 1 & 19 & $\mathbf{1}$ \\
\hline PTI & 0 & 0 & 1 & $\mathbf{1}$ \\
\hline PTA & 0 & 0 & 1 & $\mathbf{7 1}$ \\
\hline Total por Resultado & $\mathbf{2 3}$ & $\mathbf{3}$ & $\mathbf{4 5}$ & \\
\hline
\end{tabular}


Para o revisor DAPS, foi gerado um gráfico (Figura 8) que ilustra a quantidade de observações relacionadas a cada categoria. Esta solução não foi adotada para os demais revisores, pois estes não usaram o material fornecido para inclusão dos comentários de forma adequada, possibilitando esta análise estatística, porém sem comprometer a análise dos processos.

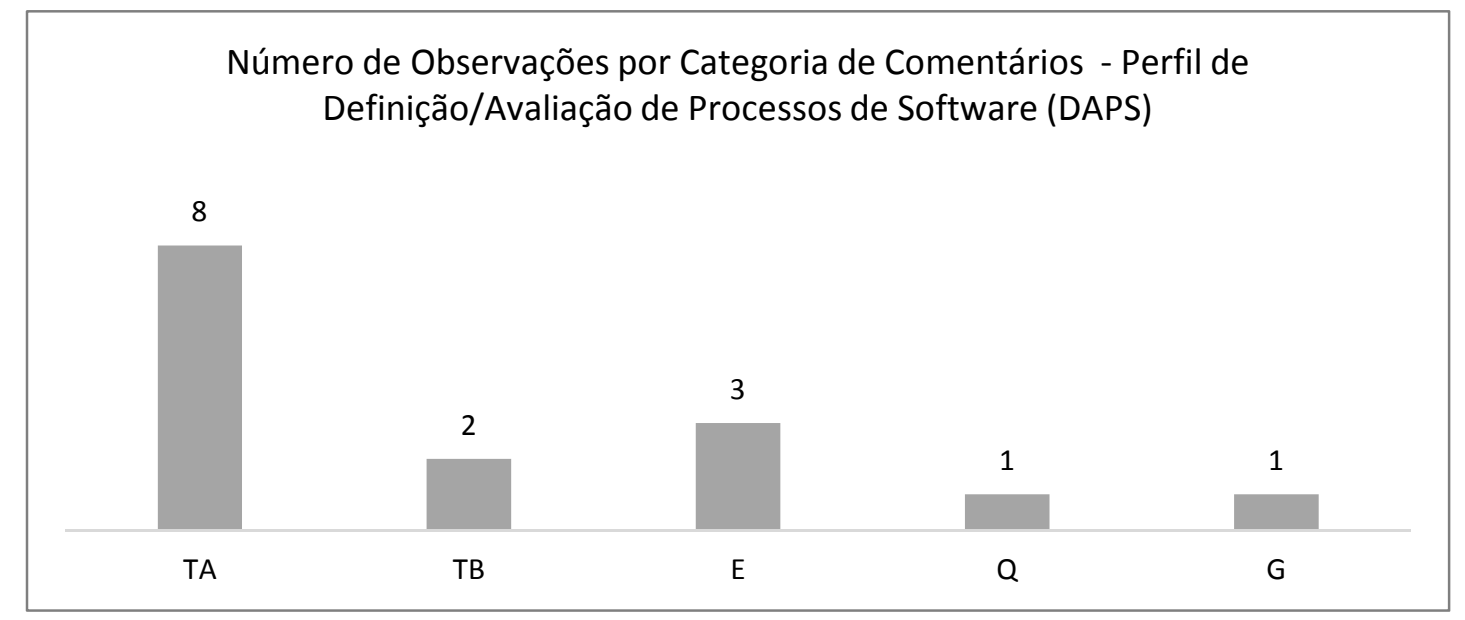

Figura 8. Número de Observações por Categoria de Comentários do Revisor DAPS.

O revisor GRH contribuiu com várias observações no processo de Gerência de Recursos Humanos de Teste que estavam relacionadas a praticamente todos os campos de descrição das atividades, como nome de atividades, papéis alocados, correção de critérios de entrada e saída, artefatos utilizados e práticas sugeridas. Muitas observações não se aplicavam ao contexto ou não foram atendidas por serem um pouco vagas (sem sugestão de ação corretiva ou descrição mais detalhada que levasse à solução) ou se tratarem de decisões tomadas durante a pesquisa. Nesse último caso, apenas foram incluídas as justificativas dessas decisões ao longo dessa dissertação. Além disso, ele fez várias sugestões relacionadas ao processo de testes adotado, inclusive para mudança da notação utilizada nos diagramas. No entanto, como os diagramas dos processos de apoio precisam se comunicar com o processo de testes adotado, optou-se por manter a mesma notação utilizada para evitar conflitos. As demais observações foram aceitas e corrigidas.

O revisor GRI também sugeriu algumas alterações relacionadas à modelagem do processo de testes utilizado. No entanto, além desse não ser o foco da revisão, elas teriam um custo de alteração muito alto em relação ao benefício para os processos de apoio, que são o foco desse trabalho. Por esse motivo, não foram atendidas. As observações sobre o Processo de Gerência de Riscos de Teste versavam principalmente sobre a divisão de atividades entre riscos de produto e de projeto, sobre o papel responsável e o nome dado a algumas atividades e inconsistências entre os artefatos requeridos/produzidos e a descrição do processo. A maioria das observações foi atendida. No entanto, algumas contrariavam os modelos de maturidade TMMi e MPT.BR que estavam sendo seguidos e optou-se por deixar alinhado com essas referências.

O revisor PTI fez um comentário de categoria Q (Questionamento) a respeito do papel atribuído como responsável por algumas atividades do Processo de Gerência de Riscos de Teste, onde o responsável era o Analista de Teste. Segundo o revisor, o responsável deveria ser algum papel de liderança, como por exemplo, o Gerente de Teste. A observação foi atendida. 
O revisor PTA observou que faltava detalhar como preencher um dos campos da planilha existente no Plano de Recursos Humanos de Teste. O comentário foi registrado como categoria TB (Técnico Baixo) e foi resolvido.

Em resumo, os resultados da revisão contribuíram bastante para o trabalho possibilitando a correção dos itens a partir das observações, que em sua maioria se relacionavam a termos inadequados e modelagem inconsistente, trazendo mais confiabilidade para os processos que foram especificados. De um conjunto de 71 observações realizadas pelos revisores, 48 (cerca de 67\%) foram completamente ou parcialmente atendidas, o que demonstra que os processos evoluíram bastante após as correções, apresentando assim, indícios de sua viabilidade para aplicação em projetos reais da indústria. As observações atendidas visavam a melhoria da descrição dos elementos dos processos (tais como a descrição da atividade, critérios de entrada e saída, utilização de termos adequados a cada área), sua representação gráfica e integração ao processo de testes. As observações não atendidas visavam, em geral, ajustes no processo de testes, mas este não era o foco de avaliação, e por isso não foram consideradas.

Após os ajustes realizados, os documentos foram retornados aos avaliadores para uma segunda avaliação a fim de confirmar que suas sugestões foram atendidas (ou justificadas, quando não atendidas). Todos aceitaram a segunda revisão e concordaram com a nova versão dos documentos avaliados.

O material completo produzido na revisão por pares e a lista com todas as contribuições fornecidas pelos revisores, podem ser obtidos em www.icomp.ufam.edu.br/experts/processosapoio.

Este estudo representou a primeira etapa visando a avaliação dos processos propostos. Aplicações dos processos em projetos reais na indústria estão sendo planejadas visando maior amadurecimento de suas atividades, artefatos e práticas sugeridas.

\section{Considerações Finais e Trabalhos Futuros}

Segundo normas e modelos de maturidade relacionados à qualidade de software, os processos de apoio são fatores importantes para a obtenção da qualidade esperada nos processos de uma organização. No entanto, a definição e implantação destes processos pode representar um risco para uma organização, caso não estejam bem fundamentados. Em geral, a literatura técnica e relatos da indústria destacam as aplicações destes processos de apoio ao processo de desenvolvimento de software. No entanto, pouca atenção tem sido dada à sua aplicação de forma integrada ao processo de testes, processo este fundamental para a obtenção da qualidade de um produto de software.

Neste trabalho, foram apresentados dois processos de apoio gerencial (de riscos e de recursos humanos) a serem instanciados para uma organização de software de forma integrada ao processo de testes, definidos a partir da análise de modelos de maturidade, normas e corpos de conhecimento disponíveis na literatura técnica para o processo de teste ou aplicáveis de forma geral a processos de software. Como principal contribuição, os processos especificados podem ser utilizados por uma organização em seus projetos de teste, identificando atividades necessárias, papéis responsáveis pelas atividades, artefatos produzidos e, principalmente, os pontos de integração entre estes processos de apoio e o processo de teste de software.

Para analisar a viabilidade desses processos, em relação ao seu conteúdo nas áreas de gerência de riscos e gerência de recursos humanos e em relação à sua estrutura e modelagem, foi conduzida uma revisão por pares com especialistas da indústria e da academia, visando obter sugestões de melhorias e correções necessárias para que os 
processos fossem aplicáveis. Os resultados contribuíram bastante para a evolução dos processos e acredita-se que, devido ao atendimento de mais de $60 \%$ das observações feitas pelos revisores, o estado atual dos processos possa contribuir para um gerenciamento mais adequado (menos suscetível a riscos inesperados e mau gerenciamento de recursos humanos) do processo de testes de software.

As principais contribuições oferecidas por esta pesquisa à comunidade de teste de software são: (1) a especificação e adequação dos processos de Gerência de Riscos e Gerência de Recursos Humanos para apoiar o gerenciamento do Processo de Testes, com base em modelos, normas e padrões de qualidade amplamente aceitos no meio acadêmico e industrial; (2) o mapeamento sistemático sobre o cenário acadêmico atual em relação aos processos Gerência de Riscos, Gerência de Recursos Humanos e Gerência de Portfólio como apoio ao gerenciamento do Processo de Testes; (3) o desenvolvimento e disponibilização de um pacote de avaliação de processos a partir da técnica de revisão por pares, composto pelo material desenvolvido para a avaliação dos processos desse trabalho (checklists, planilha de respostas, etc) e pelo procedimento de avaliação adotado, podendo ser adaptado para a revisão de outros processos no contexto de testes de software.

Algumas limitações foram observadas no decorrer da pesquisa. Por questão de espaço, não é possível detalhar ambos os processos apresentados neste artigo. Assim, o detalhamento completo dos dois processos de apoio definidos neste trabalho pode ser obtido em www.icomp.ufam.edu.br/experts/processosapoio. Outra limitação se refere à natureza da abordagem proposta, que não permitiu que os processos de apoio fossem executados e avaliados em um cenário real por conta do oneroso tempo necessário para se utilizar processos dessa natureza do início ao fim em projetos reais. Uma ou mais avaliações em um cenário real são necessárias para se garantir a aplicabilidade desses processos para a indústria. Além disso, os resultados obtidos com a avaliação da abordagem por meio da revisão por pares não são conclusivos, que além de contar com um número reduzido de participantes, levam em consideração o conhecimento, experiência e preferências de cada revisor, o que pode divergir de um especialista para outro, apesar de diversas colocações terem sido unânimes. Por fim, foram especificados apenas um subconjunto de processos de apoiam a parte gerencial do Processo de Testes de Software. Outros processos de apoio poderiam ser especificados para contribuir com a gerência das atividades de testes, como por exemplo, o processo de gerência de portfólio, que não foi especificado nesse trabalho devido à falta de informações sobre o seu apoio para o processo de testes.

Apesar de não serem conclusivos, os dados obtidos na avaliação da abordagem resultando na correção e evolução dos processos de apoio indicam que a abordagem é viável para o que se propôs realizar. Assim, como próximos passos estão previstos, primeiramente, a realização de novas avaliações em cenários reais para possibilitar a observação do seu comportamento, das suas contribuições e de itens a serem ajustados, resultando no amadurecimento dos processos. Ainda estão previstas a especificação e adequação de outros processos de apoio que atendam à parte gerencial dos testes, como os processos previstos no guia PMBOK (PMI, 2013) (processos de gerência da qualidade, de portfólio, de custos, de tempo, entre outros) e processos que atendam ainda a parte técnica do processo de testes de software, como por exemplo, processo de gerência de configuração e processo de gerência de reutilização dos ativos de teste.

\section{Agradecimentos}

Os autores agradecem à FAPEAM pelo apoio financeiro para a condução desta pesquisa. 


\section{Referências Bibliográficas}

ABNT - Associação Brasileira de Normas Técnicas. (1998). NBR ISO/IEC 12207: Tecnologia de informação - Processos de ciclo de vida de software.

Amland, S. (2000). Risk-based testing: risk analysis fundamentals and metrics for software testing including a financial application case study. In: Journal of Systems and Software, Vol. 53 (3), pp. 287-295. DOI=10.1016/S0164-1212(00)00019-4.

Barcellos, M. P. (2009). Uma Estratégia para Medição de Software e Avaliação de Bases de Medidas para Controle Estatístico de Processos de Software em Organizações de Alta Maturidade. Tese de D.Sc., COPPE/UFRJ, Brasil.

Bertolino, A. (2004). The ( $\mathrm{Im})$ maturity Level of Software Testing. In: SIGSOFT Software Engineering Notes, Vol. 29 (5), pp 1-4, DOI=10.1145/1022494.1022540.

Boycan, S.; Chernak, Y. (2005). Implementing configuration management for software testing projects. The Journal of Defense Software Engineering, pp. 4-9.

Bubevski, V. (2010). An Application of Six Sigma and Simulation in Software Testing Risk Assessment, In: International Conference on Software Testing, Verification and Validation (ICST), IEEE Publisher, pp. 295-203, DOI: 10.1109/ICST.2010.23.

Chen, Y.; Probert, R. L.; Sims, D. P. (2002). Specification-based Regression Test Selection with Risk Analysis. In Proceedings of the 2002 conference of the Centre for Advanced Studies on Collaborative research (CASCON'02), pg 1, IBM Press.

Dias-Neto, A.C. (2006). Uma Infra-Estrutura Computacional para Apoiar o Planejamento e Controle de Testes de Software. Dissertação de M.Sc., COPPE/URFJ, Brasil.

Ericson, T., Subotic, A., Ursing, S. (1997). TIM - A Test Improvement Model, In: Software Testing, Verification and Reliability, Vol. 7 (4), pp. 229-246. DOI: $10.1002 /($ SICI)1099-1689.

Gelperin, D., Hetzel, B., (1988). The Growth of Software Testing, Communications of the ACM, Vol. 31(6), p. 687-695. DOI=10.1145/62959.62965.

IEEE Computer Society. (2008). IEEE 829: Standard for Software Test Documentation.

ISO/IEC. (2008). ISO/IEC 12207: System and Software Engineering - Software Life Cycle Processes.

ISO/IEC/IEEE 29119-2 - Software and system engineering - Software Testing - Part 2: Test Processes. 2013.

Kitchenham, B.; Charters, S. (2007). Guidelines for Performing Systematic Literature Reviews in Software Engineering, v.2.3. RT, Evidence-Based Software Engineering.

Larsson, D.; Bertilsson, H.; Feldt, R. (2008). Challenges and solutions in test staff relocations within a software consultancy company. In: International Conference on Software Testing, Verification and Validation (ICST), IEEE Publisher, pp. 423-431, DOI: 10.1109/ICST.2008.28.

Lazic, L.; Mastorakis, N. (2005). RBOSTP: Risk-based optimization of software testing process Part 1. WSEAS Transactions on Information Science and Applications, p. 695.

Li, Z.; Mao, H.; Chen, Y.; Liu, X.; Xu, T. (2013) An empirical exploration of effective management in software-testing outsourcing. In: Advances in information Sciences and Service Sciences (AISS), Vol. 5 (3), 453-461, DOI: 10.4156/AISS.vol5.issue3.53.

Mäntyniemi, A.; Maki-Asiala, P.; Karki, M. (2005). A Process Model for Development and Utilization of Reusable Test Assets. Proceedings of the International Conference on Software Engineering Research and Practice (SERP 2005), Las Vegas, Nevada, USA, June 27-29, 2005, Volume 1, pp. 309-315. 
Miranda, B.; Iyoda, J.; Meira, S. Test Case Recommender: um sistema de recomendação para alocação automática de testes baseada no perfil do testador. IV Brazilian Workshop on Systematic and Automated Software Testing (SAST 2010), 2010, Natal, Brazil.

Myers, G. J. The Art of Software Testing. Segunda edição, 2004.

Paul, R. (2001). End-to-End Integration Testing. Proceedings Second Asia-Pacific Conference on Quality Software (APAQS, 2001), pp. 0211, doi:10.1109/APAQS.2001.990022.

Paulk, M.; Weber, C.; Curtis, B.; Chrissis, M. B. (1995). The Capability Maturity Model: Guidelines for Improving the Software Process. Addison-Wesley Professional.

PMI - Project Management Institute (2013). A Guide to the Project Management Body of Knowledge (PMBOK® Guide) $-5^{\text {th }}$ Ed.

Pressman, R. S. (2010). Software Engineering: A Practitioner's Approach, $7^{\text {th }}$ Ed.

SEI - Software Engineering Institute (2010). CMMI for Development (CMMI-DEV).

Sherer, S.A. (1991). A cost-effective approach to testing. IEEE Software, Vol 8 (2), pp. 34-40. DOI=10.1109/52.73747.

SOFTEX - Associação para Promoção da Excelência do Software Brasileiro. (2012). MPS.Br - Melhoria do Processo do Software Brasileiro, Guia Geral MPS de Software.

SOFTEX Recife - Centro de Excelência em Tecnologia de Software do Recife. (2011). MPT.Br - Melhoria do Processo de Teste Brasileiro, Guia de Implementação, N.1 e 2.

Sogeti. TPI Next, Business Driven Test Process Improvement. UTN Publishers, Netherlands, 2009.

Sommerville, I. (2007). Engenharia de Software, Pearson Education, 9 ${ }^{\text {a }}$ Ed.

Souza, E.; Gusmão, C.; Venâncio, J. (2010). Risk Based Testing - A Case Study. Seventh International Conference on Information Technology. Las Vegas, Nevada, USA, IEEE Publisher, pp. 1032-1037, DOI=10.1109/ITNG.2010.203.

Stoelinga, M.; Timmer, M. (2009). Interpreting a Successful Testing Process: Risk and Actual Coverage. In: IEEE International Symposium on Theoretical Aspects of Software Engineering (TASE), Tianjin, pp. 251-258, DOI= 10.1109/TASE.2009.26.

TMMi Foundation (2012). Test Maturity Model integration (TMMi).

Trovão, J. C; Dias-Neto, A. C. (2014). Processos de Apoio Gerencial Integrados ao Processo de Teste de Software. In: X Workshop Anual do MPS, SOFTEX, v. 10, Campinas.

Villela, K. (2004). Definição e Construção de Ambientes de Desenvolvimento de Software Orientados à Organização. Tese de D.Sc. COPPE/UFRJ, Brasil.

Yoon, H., Choi, B. (2011). A test case prioritization based on degree of risk exposure and its empirical study. In: International Journal of Software Engineering and Knowledge Engineering, Vol. 21, pp. 191-209, DOI: 10.1142/S0218194011005220. 